\title{
Small catchment scale Mo isotope balance and its implications for global Mo isotope cycling
}

Th. F. Nägler ${ }^{1 *}$, M.-C. Pierret ${ }^{2}$, A. R. Voegelin ${ }^{1}$, T. Pettke ${ }^{1}$, L. Aschwanden ${ }^{1}$, I.M.Villa ${ }^{1,3}$

${ }^{1}$ Institut für Geologie, Universität Bern, Baltzerstrasse 1+3, 3012 Bern, Schweiz

${ }^{2}$ Laboratoire d'Hydrologie et de Géochimie de Strasbourg, EOST, Université de Strasbourg/CNRS, 1 rue Blessig, $\square 67084$ Strasbourg, France

${ }^{3}$ Centro Universitario Datazioni e Archeometria, Università di Milano Bicocca, 20126 Milano, Italy

\begin{abstract}
The mass balance of molybdenum (Mo) was studied in the Strengbach catchment. Monitoring of rainfall, vegetation, and soil characteristics in this $0.8 \mathrm{~km}^{2}$ catchment was started decades ago. We present Mo concentrations and isotope compositions of about 60 samples including bedrock types, perennial springs, soil profiles, roots and leaves, and the outflowing brook. Both stream waters and bedrocks have Mo concentrations at least one order of magnitude lower than global averages. The Mo isotope composition of topsoils, foliage, litter, and roots is rather homogeneous. Net biological fractionation is thus subordinate to differences in the Mo sources. Efficient Mo recycling from organic litter to plants keeps Mo bioavailable. The Mo and Sr isotope data, are used to identify the source(s) of Mo and Sr and their (transient) storage within the catchment. The resulting best model identifies rock weathering and seawater derived aerosol as the principal Mo sources. Moreover, soil in the Strengbach catchment has reached steady state for Mo (the time constant to achieve soil steady state is calculated to be in in the order of 50 years) where the Mo isotope compositions of fluxes to and from the catchments soil are identical.
\end{abstract}

\section{Introduction}

Molybdenum (Mo) is the most abundant transition metal in the ocean and is essential for nitrogen metabolism of organisms (Stiefel, 2005; Dellwig et al., 2007). In oxic ocean water, the predominant $\mathrm{Mo}$ species is soluble molybdate oxyanion, $\mathrm{MoO}_{4}{ }^{2-}$. Its low chemical reactivity results in a comparatively long oceanic residence time of several hundred ka (Colodner et al., 1995; Emerson and Huested, 1991; Miller et al., 2011). This rendered Mo isotope systematics increasingly important in reconstructing the oceanic and atmospheric 
redox history (Arnold et al., 2004; Baldwin et al., 2013, Czaja et al., 2012; Dickson et al., 2017; Duan et al., 2010; Eroglu et al., 2015; Kendall et al., 2009, 2010, 2011; Kurzweil et al., 2016; Pearce et al., 2008, 2010b; Siebert et al., 2003; Voegelin et al., 2010; Wille et al., 2007, 2008).

The main Mo input to the ocean is continental runoff (Morford and Emerson, 1999; McManus et al., 2002, 2006). Early studies (Barling et al., 2001; Siebert et al., 2003) assumed that continental runoff had a roughly constant long-term Mo isotope composition of $\delta^{98 / 95} \mathrm{Mo} \approx 0$, based on the initially available Mo isotope composition of molybdenites and crustal igneous rocks as the principal continental Mo sources. (Please note: Mo isotope data are reported as permil deviation from NIST SRM 3134 defined to have $\delta^{98 / 95} \mathrm{Mo}=0.25 \%$, (Nägler et al., 2014; cited data are renormalized where necessary).

This assumption was challenged by Archer and Vance (2008), who reported that river waters have variable Mo concentrations of between 2 and $511 \mathrm{nmol}$ and variable $\delta^{98 / 95}$ Mo between 0.2 and $2.3 \%$, averaging $0.7 \%$. Subsequent papers confirmed the large spread in Mo concentrations and Mo isotope composition in rivers (Pearce et al., 2010a; Neubert et al., 2011; Voegelin et al., 2012).

One argument made by Archer and Vance (2008) was that the Mo isotopic heterogeneity of river water was due to pedogenesis, whereby isotopically light Mo was hypothesized to be permanently trapped in secondary phases in soils. This argument was embraced by Pearce et al. (2010a) and Wang et al. (2015). In contrast, Neubert et al. (2011) documented an overlap between river water Mo isotope composition and the respective bedrocks of the catchments they studied. They concluded that Mo isotope fractionation during weathering and pedogenesis was a minor effect. Even if light Mo isotopes initially are preferentially retained in soil, erosion will eventually liberate them again. Once steady state between soil formation and soil erosion is attained, the net isotope fractionation is zero. Consequently a bias of the runoff relative to the bedrock in a catchment can only be maintained on time-scales shorter than the establishment of a steady-state soil thickness, and thus cannot be considered as a long-term geological process.

Voegelin et al. (2012) investigated a small catchment in the Massif Central (France) underlain exclusively by igneous crustal rocks and documented that incongruent weathering was a more efficient cause of Mo isotope fractionation than soil formation. Laboratory leaching of bedrock basalt yielded a leach solution enriched in heavy Mo isotopes to the same extent as the natural river waters. These authors proposed that the source of isotopically heavy Mo 
were magmatic sulfides, which have Mo concentrations up to $250 \mu \mathrm{g} / \mathrm{g}$. As sulfides are much more soluble than magmatic silicates, they are expected to vastly dominate the dissolved Mo river load, whereas silicates remained mostly in the particulate load.

Along-stream profiles (Archer and Vance, 2008; Pearce et al., 2010a; Neubert et al., 2011) show that the Mo isotope composition of river waters is mainly established in the source area. Intra-fluvial processes such as, precipitation of secondary minerals in the river bed and/or in lakes (Villa et al., 2017) or scavenging by suspended matter (Wang et al., 2015), appear to be of subordinate importance in most rivers.

Atmospheric Mo input has been investigated by Pearce et al. (2010a), Marks et al. (2015) and King et al. (2016). Pearce et al. (2010a) observed the heaviest fluvial $\delta^{98 / 95}$ Mo of their study area, $1.8 \%$, in a river supplied by glacial meltwater. This heavy Mo isotope composition was interpreted as deriving from sea-spray advection to the glacier (either by direct aerosol transport or by incorporation into rain/snow clouds). Seawater has a heavy $\delta^{98 / 95}$ Mo of $2.3 \%$ and thus is a plausible source of isotopically heavy Mo. Marks et al. (2015) studied a forest ecosystem and observed that atmospheric Mo influx supplied one order of magnitude more Mo than litterfall. There is strong evidence that the binding of molybdenum to organic matter reduces the loss of micronutrient molybdenum from soils (Wichard et al., 2009; Wang et al., 2015). Marks et al. (2015) showed that Mo bound to organic matter accounts for an average of one-third of the bulk Mo of soils in their study area. Analyses of the speciation of molybdenum in Arizona and New Jersey forest soils (Wichard et al., 2009) indicate that Mo forms strong complexes with plant-derived tannins and tannin-like compounds.

Anthropogenic aerosols are a potential additional source of Mo of variable isotope composition in heavily industrialized areas (Lane et al., 2013; Chappaz et al., 2012).

Of special relevance for the present study is the characterization of ${ }^{87} \mathrm{Sr} /{ }^{86} \mathrm{Sr}$ isotope ratio in bedrock, spring- and river water. Since ${ }^{87} \mathrm{Sr}$ is the radiogenic daughter of ${ }^{87} \mathrm{Rb}$, whereas ${ }^{86} \mathrm{Sr}$ is non-radiogenic, the ${ }^{87} \mathrm{Sr} /{ }^{86} \mathrm{Sr}$ ratio depends on the age of a rock and on its parent/daughter $(\mathrm{Rb} / \mathrm{Sr})$ element ratio, and is thus highly variable amongst terrestrial rocks. Probst et al. (2000) used $\mathrm{Sr}$ isotope compositions to model the relative contributions of weathering and atmospheric dust influx to the Ca mass balance of the Strengbach catchment studied here. They attributed net losses of $\mathrm{Sr}$ from the catchment to exchange and weathering processes in soils and saprolite. Consequently this catchment was not in a steady state at least for $\mathrm{Ca}$ and $\mathrm{Sr}$ at the sampling period of the respective waters (late 1980s to early 1990s.). The neutralization of acid atmospheric inputs led to strong depletion of the exchangeable pool of 
cations in the soils and accounts for the base cation losses from the catchment $\left(2.8 \mathrm{keq} \mathrm{ha}^{-1} \mathrm{a}^{-1}\right.$, Probst et al., 1992a,b, 1995b).

In order to assess the relative importance of these processes, we selected a well-studied catchment, remote from direct industrial or agricultural activities so as to minimize anthropogenic sources of Mo. The mass balance of river waters and of the surface processes within the catchment has been documented over several years of continuous monitoring. Extrapolating this knowledge of the catchment to the Mo mass balance endeavors to quantify the Mo budget of bedrock erosion, atmospheric input, and pedogenesis, both inorganic and biologically controlled. Within our study on the Mo sources and budgets of the entire catchment, we also address internal Mo cycling.

\subsection{The Strengbach Catchment}

It is self-evident that large rivers average the chemical composition of the sum of their tributaries, hence they smooth out potential scatter of the Mo isotopic composition. This is the opposite of what is required for a fine-scale understanding of surface processes. We therefore chose the comparatively small $\left(0.8 \mathrm{~km}^{2}\right)$ Strengbach catchment in the Vosges mountains (France). This catchment has been studied and regularly monitored during 32 years by the Observatoire Hydrogéochimique de l'Environnement (http://ohge.unistra.fr). It is located at altitudes between 880 and $1150 \mathrm{~m}$ a.s.l. Forest covers $90 \%$ of the area and is composed of about $80 \%$ spruce (mainly Picea Abies L.) and $20 \%$ beech (Fagus Sylvatica). Eleven perennial springs (Fig. 1) feed the Strengbach streamlet (Pierret et al., 2014).

Bedrock lithology of the catchment is rather homogeneous and only consists of crystalline silicate rocks: sillimanite gneiss, cordierite-bearing granite, and aplitic microgranite, including a dated, alkali feldspar rich Hercynian granite (Boutin et al., 1995). Hydrothermal alteration (180 Ma; Fichter et al., 1998) transforming K-feldspar and muscovite into illite/sericite and quartz and almost completely consuming biotite and albite (El Gh'mari, 1995) is strongest for the granite from the northern slope.

A sandy saprolite separates soil and granite. Its thickness varies between 1 and $9 \mathrm{~m}$. On the rainier southern slope it is generally thicker (El Gh'mari, 1995), and is thickest in a depression zone near the four springs labeled CS in figure 1. The overlying soil system is up to $1 \mathrm{~m}$ thick. Acidity of the soils results both from natural (podsolization) and anthropogenic causes. Soil solutions close to the surface $(0-5 \mathrm{~cm})$ are also acidic $(\mathrm{pH}=4.0$; Prunier et al., 2016). In deeper soils the acidity is progressively neutralized by mineral dissolution and $\mathrm{H}^{+}$-cation 
exchanges. The annual precipitation was $1442 \mathrm{~mm}$ and the annual runoff was $723 \mathrm{~mm} / \mathrm{a}$, or $22,8 \mathrm{~L} \mathrm{~s}^{-1} \mathrm{~km}^{-2}$ for the study period of two years (OHGE data).

From the early 1980s symptoms of forest decline have been recognized. Spruce yellowing has been related to magnesium deficiencies (Landmann et al., 1987) and early studies addressed the impact of acid rain on the forested ecosystem (Dambrine et al., 1991, 1992a, b; Probst et al., 1990, 1992a, b). Since 1986, annual sulfur deposition has decreased from 2 t of $\mathrm{S}$ in 1986 to $260 \mathrm{~kg}$ in 2015 at the Strengbach catchment (Pierret et al.; submitted), corresponding to a drop of $87 \%$. For this period, average annual $\mathrm{pH}$ levels changed from 4.4 to 5.1 for rain and from 6.1 to 6.5 for the stream at the catchment outlet. Similarly, average annual sulfate concentrations decreased from 0.028 to 0.007 and from 0.102 to $0.040 \mathrm{mmol} / 1$ for rain and stream at the outlet respectively (Pierret et al., accepted). In line, the average $\mathrm{pH}$ of Strengbach rain and stream waters were 5.1 and 6.5, respectively for the sampling period of the present study (2009-2010).

\subsection{Sample description and analytical techniques}

About 60 samples were collected in the Strengbach catchment. These include samples from the trunk stream and different springs in the catchment, bedrocks, soil profiles and organic samples (see Figs. 1,2 and 3). The springs SG, ARG, RH, BH, CS3 and CS4 are located on the northern slope and the springs CS1, CS2, SH and RUZS emerge at the southern slope (Fig. 1). The spring RUZS is situated in the humid zone at the bottom of the catchment near the outlet (saturated area, Fig. 1) and covered by dense grass vegetation. RS corresponds to the Strengbach stream at the outlet of the catchment and represents the sum of all measured spring waters. RAZS is a sampling site located along the Strengbach upstream of the humid zone.

The soil profile sampled at the spruce plot (VP) is located at $1050 \mathrm{~m}$ altitude on the northern slope (Figs. 1,4) and belongs to the Alocrisol type (brown acidic soil). Acid mull/moder humus of about $2 \mathrm{~cm}$ is above the Ah dark brown horizon $(0-5 \mathrm{~cm}$ depth) that contains a very large number of fine roots and polyhedric and micro-crumbly structure, and represents a sandy clay loam soil. The AE horizon $(5-10 \mathrm{~cm}$ depth) is brown/yellow sandy clay loam soil, with many roots and about 10\% gravel. The B horizon (11-60 cm depth) is a grey-reddishbrown, tight and compact soil with a sandy clay loam texture with $10-20 \%$ gravel and many roots extending to about $50 \mathrm{~cm}$ depth. The $\mathrm{C}$ horizon $(60-125 \mathrm{~cm})$ is a grey-red soil with much higher gravel contents and fewer roots. 
The soil profile sampled at the beech plot (HP) located at $1000 \mathrm{~m}$ altitude on the southern slope belongs to the ochreous podzol type (ochreous brown podzolic soil). The moder humus is about $3-4 \mathrm{~cm}$ thick. The Ah blackish brown horizon $(0-10 \mathrm{~cm})$ is very porous, contains a very large number of fine roots, has a micro-crumbly structure and is classified as a sandy clay loam soil. The AE horizon (10-25 cm depth) is beige-grey sandy clay loam soil, hardly compact, very porous and with many roots. The B/BPs horizon $(25-55 \mathrm{~cm}$ depth) is a yellowish orange compact and friable soil, with polyedric structure, a loamy sand texture, with $25 \%$ gravels and many roots. The $\mathrm{C}$ horizon $(55-140 \mathrm{~cm})$ is a light yellowish-orange, compact and friable soil with a loamy sand texture, particle structure, fewer roots and up to $50 \%$ of gravel.

Organic material was sampled from both soil profile locations, including leaf litter, roots and spruce needles, to get an overview of potential Mo isotope fractionation in the biological cycle. Moreover nine rock samples (6 fresh rocks and 3 weathered rocks or rims) were collected at different sites of the Strengbach catchment in order to have a representative sampling of the different granite types.

\subsection{Methods}

Sampling and sample preparation:

Water samples for Mo isotope analytics were filtered through a $0.45 \mu \mathrm{m}$ Nalgene ${ }^{\circledR}$ membrane filter and collected in LDPE bottles and acidified immediately to $\mathrm{pH}<2$ with distilled nitric acid. Water samples for elemental analyses were collected in polyethylene (HDPE) bottles and filtered the same day through a $0.45 \mu \mathrm{m}$ pore diameter membrane.

Rock samples were cleaned and subsequently crushed in a hydraulic press. Bulk rock samples were treated with concentrated $\mathrm{HCl}$ and $\mathrm{H}_{2} \mathrm{O}_{2}$ and $\mathrm{HF}+\mathrm{HNO}_{3}$ dissolution steps to ensure complete digestion of the silicate matrix (Siebert et al., 2001; Wille et al., 2007).

Soil material was dried at $60{ }^{\circ} \mathrm{C}$ and subsequently sieved below $2 \mathrm{~mm}$ to separate it from rock pebbles and root material. All the data on soil were obtained on the fraction $<2 \mathrm{~mm}$.

Roots were cleaned in an ultrasonic bath and rinsed repeatedly with high purity $\mathrm{H}_{2} \mathrm{O}$ to remove any residual soil particles.

Soil and root samples were digested using multiple $\mathrm{HNO}_{3}$ and $\mathrm{HF}$ steps closely following the procedure described in Cenki-Tok et al. (2009).

Chemical Mo purification (all samples): Mo was purified using the separation procedure described in Siebert et al. (2001) and Wille et al. (2007), modified for low concentration 
samples (see also Voegelin et al., 2009). Only an outline is given here: $\mathrm{a}^{100} \mathrm{Mo}-{ }^{97}$ Mo double spike was added to the sample prior to chemical purification. $\mathrm{H}_{2} \mathrm{O}_{2}$ was added to keep Mo in its highly soluble $\mathrm{Mo}^{6+}$ state. Dried sample solutions were re-dissolved in $4 \mathrm{M} \mathrm{HCl}$ and passed through an anion exchange column ( $1 \mathrm{ml}$ Dowex $\left.^{\mathrm{TM}} 1 \mathrm{X} 8 \mathrm{resin}\right)$. Mo was eluted with 6 $\mathrm{ml} 2 \mathrm{M} \mathrm{HNO}_{3}$. A subsequent cation exchange column (Dowex 50WX8 resin) was additionally used depending on the sample matrix. Procedural Mo blanks $(<1 \mathrm{ng})$ are small compared to the typical total amount of sample Mo processed (mostly $>60 \mathrm{ng}$, min $20 \mathrm{ng}$ ).

The dried and purified Mo fraction was re-dissolved in $0.5 \mathrm{M} \mathrm{HNO}_{3}$ for measurement using a $\mathrm{Nu}$ instruments ${ }^{\mathrm{TM}}$ multiple collector ICP-MS. The protocol followed Siebert et al. (2001) except for use of an Apex Q desolvating nebulizer for sample introduction.

Mo isotope data are reported as permil deviation from a reference material, whereby the NIST SRM 3134 is defined to have $\delta^{98 / 95} \mathrm{Mo}=0.25 \%$ (Nägler et al., 2014).

The long-term external reproducibility of SRM 3134 and in-house reference solution is better than 0.1\%o (2 standard deviations, Siebert et al., 2001; Voegelin et al., 2009; Neubert et al., 2011; Greber et al. 2012). This uncertainty was used for all water results in the figures unless limits on individual measurements were larger. Table 1 lists $\delta^{98 / 95}$ Mo of the water samples with $2 \sigma$ errors of the measurements. Replicates of higher concentration samples indicate a better reproducibility for the measurement period.

Eluted matrix solutions from the Mo anion column separation were evaporated and $\mathrm{Sr}$ was separated on miniaturized $\mathrm{SrSpec}^{\mathrm{TM}}$ columns. Sr isotope compositions were measured at the University of Bern on a Thermo Fisher TRITON thermal ionization mass spectrometer. The external reproducibility of the NIST SRM 987 standard was $0.710235 \pm 0.000029$ $(2 \sigma ; \square \square \square \square)$ during the two days measuring period of the present analyses.

Element analyses of waters: Analytical procedures are described in Pierret et al. (2014), so only a brief description is given here. Major element concentrations were determined by ion chromatography and ICP-AES and the trace element concentrations were determined by ICPMS. The analytical uncertainty is $\pm 2 \%$ for the major elements and $\pm 5 \%$ for the trace element concentrations. The DOC was determined using an organic carbon analyser with an uncertainty of 5 to $10 \%$. The uncertainty of the $\mathrm{pH}$ measurement was \pm 0.02 units. Complementary water samples were analyzed for major ions $\mathrm{Na}^{+}, \mathrm{K}^{+}, \mathrm{Ca}^{2+}, \mathrm{Mg}^{2+}, \mathrm{F}^{-}, \mathrm{Cl}^{-}$, $\mathrm{NO}_{3}{ }^{-}$, and $\mathrm{SO}_{4}{ }^{2-}$ in Bern using a a Metrohm ${ }^{\mathrm{TM}} 861$ Advanced Compact Ion Chromatograph. 
Soil parameters (CEC, pH, OM, Tables 2a,b) were determined in the national soil analysis service from INRA (French National Institute for Agricultural Research / LAS Laboratoire d'Analyse des Sols). Soil-pH was measured in a solution of $10 \mathrm{~g}$ of dried soils in $50 \mathrm{ml}$ of deionized water (NF ISO 10390). Mn or Fe concentrations (Table 2a) correspond to the chemical concentration of whole soils after calcination and fusion with lithium-tetraborate in the LHYGES laboratory. Exchangeable cations concentrations (Table 2a,b) have been determined after shaking $2.5 \mathrm{~g}$ of soil with $100 \mathrm{ml}$ of acetate ammonium solution at $1 \mathrm{~mol} / \mathrm{l}$. The filtered solution is then measured and concentration determined using ICP-AES (AFNOR NF X 31-108) in LAS of INRA ARRAS laboratory (Ciesielski et al., 1997).

Laser ablation ICP-MS analyses of bedrock minerals: LA-ICP-MS analyses were performed at the University of Bern on minerals of one selected granite using a GeoLas-Pro $193 \mathrm{~nm}$ ArF excimer laser system in combination with a Perkin Elmer Elan DRC-e quadrupole mass spectrometer. Instrumental conditions were similar to those reported in Pettke et al. (2012). Bracketing standardization using NIST SRM 610 was used for instrument sensitivity calibration and drift correction. Internal standardization was done by summing major element oxides to $100 \mathrm{wt}-\%$ minus water. Data quantification used the SILLS software package (Guillong et al., 2008).

\section{Results and Discussion at the plot scale}

\subsection{Soil profiles and organic matter}

Mo concentrations are the highest in the topsoil. For both soil profiles, under spruce or beech, the $\delta^{98 / 95}$ Mo tends to decrease with increasing depth (see Fig. 4; Tables 2a and b) except for the highest value (HP at $75 \mathrm{~cm}$ depth) $\delta^{98 / 95}$ Mo correlates positively with cation exchange capacity (CEC), organic matter and carbon content (Fig. 5). Figure 6 also indicates a correlation of $\delta^{98 / 95}$ Mo with exchangeable Ca.

Samples from intermediate depth can be interpreted as a mixture between organic matter and weathered bedrock, as Carbon and organic matter contents decrease with depth. The positive correlation of $\delta^{98 / 95}$ Mo with total organic matter supports this hypothesis.

In a first systematic study of Mo isotope fractionation in soils covering a wide range in climate and degree of weathering, Siebert et al. (2015) found both light and heavy $\delta^{98 / 95} \mathrm{Mo}$ from $-0.41 \%$ to $+1.5 \%$ in bulk soil samples. Soils consistently showed lighter Mo isotope ratios associated with net loss of Mo. These authors reported a positive correlation of Mo gains and carbon contents of soils supporting the importance of Mo retention via interactions 
of Mo with organic matter (see also McManus et al., 2006; Wichard et al., 2009). Based on soils formed on Hawaiian basalts, King et al. (2016) suggested that Mo increases result from precipitation, volcanic fog, and potentially anthropogenic Mo and that the retention of Mo depends strongly on binding Mo to organic matter.

Topsoil samples of the Strengbach catchment yield $\delta^{98 / 95}$ Mo in the range of Strengbach biological litter (spruce needles [Mo] $=0.02 \mathrm{ppm} \delta^{98 / 95} \mathrm{Mo} 0.5 \pm 0.1 \%$; beech leafs litter $\left([\mathrm{Mo}]=0.05 \mathrm{ppm} \delta^{98 / 95} \mathrm{Mo} 0.7 \pm 0.1 \%\right.$, see Fig 7 , Table 3$)$. Evidently the high amount of organic matter dominates the Mo budget (Fig. 8) and hence the isotope composition in soil. Deep soil samples fall within the range of fresh bedrock granites.

Samples from intermediate depth can be interpreted as mixtures of these sources, as Carbon and organic matter content decrease with depth. The correlation of $\delta^{98 / 95}$ Mo with total organic matter (Fig. 5) supports this hypothesis. Similarly, Marks et al. (2015) found a positive correlation of exchangeable Mo with soil carbon indicating organic matter as the source of readily exchangeable Mo. In their study they examined soil, bedrock, and plant Mo variations across 24 forests in the Oregon Coast Range. Mo adsorption on organic matter was shown to result in significant Mo isotope fractionation in laboratory experiments by King et al. (2018) who investigated Mo isotope fractionation during adsorption onto insolubilized humic acid as a proxy for organic matter. At the $\mathrm{pH}$ range of the Strengbach soils $(\mathrm{pH} \approx 4)$, the liquid-solid $\Delta^{98 / 95}$ Mo was found to be about $0.8 \%$.

For the Strengbach catchment Pierret et al. (2014) suggested that physico-chemical soil processes have a subordinate impact on the chemical balance of the main cations of waters at the outlet. As an example, they report that the mean annual flux of $\mathrm{Ca}$ in soil solution at 60 cm depth represents 5 to $20 \%$ of the annual flux at the outlet, depending on the type of vegetation or soil (Cenki-Tok et al., 2009). In addition, on the basis of spatial and temporal variations of $\mathrm{Sr}$ and $\mathrm{U}$ isotopes in spring and stream water, Pierret et al. (2014) concluded that the compositions of superficial waters are mainly controlled by interactions occurring with the saprolite and bedrock, along preferential pathways. Fe concentrations vary by a factor of 2 between HP soil and VP soil (ranging between 1.2 to $2.4 \%$ and between 3.5 to $4.5 \%$, respectively), whereas the Mo concentrations are similar in both profiles.

Below organic rich topsoils, Mo concentrations in the two Strengbach soil profiles are very homogenous, even though $\mathrm{pH}$ values vary with depth (Fig. 8). In acidic soils, molybdenum is adsorbed onto mineral surfaces (Wichard et al., 2009), which should be more efficient at pH 3 
(upper soils) than at pH4 (deeper soils). However, the $\mathrm{pH}$ range my just be too small to result in significant net effects. Mo in soils is generally associated with Fe-oxyhydroxides and/or organic matter. Binding to iron oxides should lead to lighter $\delta^{98 / 95}$ Mo ratios (Goldberg et al., 2009). Results of our profiles, however, do not show a significant net effect of Fe or Mn concentration on $\delta^{98 / 95}$ Mo (Fig. 6). As a consequence the main factor controlling Mo isotope composition appears to be the organic carbon content. In its correlation with organic matter, Mo mimics exchangeable $\mathrm{Ca}$ (Fig. 6c), which is highly biologically recycled in this environment.

For mass balance reasons, the $\delta^{98 / 95}$ Mo of the initial Mo source would have to fall between organic matter and dissolved loads. As the observed $\delta^{98 / 95}$ Mo in soil of the Strengbach catchment is always above bedrock and below dissolved riverine load, the initial Mo source cannot be purely bedrock. An additional source with higher $\delta^{98 / 95}$ Mo is required. As already noted by Siebert et al. (2015) and King et al. (2016), Mo in soil can also have an atmospheric origin. This reinforces the similarity with $\mathrm{Ca}$, which shows a significant atmospheric contribution in the litter, soil horizons and soil solutions of the Strengbach catchment: The annual $\mathrm{Ca}$ flux from throughfall is higher than the annual $\mathrm{Ca}$ flux in soil solutions at $60 \mathrm{~cm}$ depth, on spruce stand as well as on beech stand (Pierret et al., submitted). The atmospheric Ca contribution at the catchment scale represents about $30 \%$ of the annual flux at the outlet (Pierret et al., submitted).

\subsection{Litter, foliage, roots}

We observe that the Mo isotope composition of foliage, litter, roots, humus, and topsoil are similar. This points to efficient recycling of Mo in the biological cycle, similar to findings for $\mathrm{Ca}$. It is also in line with the conclusion of the importance of organically bound Mo to significantly reduce Mo loss from the system (King et al., 2016; Marks et al., 2015; see above). King et al. (2018) reported that, for 10 of the 12 forested sites in the Oregon Coast Range, $\delta^{98 / 95}$ Mo of foliage were identical within $2 \sigma$ uncertainty to $\delta^{98 / 95}$ Mo in the soil.

Throughfalls under spruces or beeches have Mo concentrations ranging between 0.04 and $0.12 \mathrm{ppb}$. Mo concentrations in soil solutions are quite constant: $0.03 \mathrm{ppb}$ at $60 \mathrm{~cm}$ depth and $0.08 \mathrm{ppb}$ at $5 \mathrm{~cm}$ depth at the spruce plot and $0,01 \mathrm{ppb}$ at $70 \mathrm{~cm}$ depth and 0.03 at $10 \mathrm{~cm}$ at the beech plot (unpublished date from Strengbach data base).

The fact that Mo concentrations in deeper soil solution are lower than in throughfalls implies that a significant fraction of Mo is recycled between topsoil and $60 \mathrm{~cm}$ depth by biological uptake and/or is supplied by atmospheric input. The Mo mass balance, including soil, organic 
matter (foliage, litter, and roots) and atmospheric inputs at the catchment scale are discussed below.

\section{Results and Discussion at the catchment scale}

\subsection{Waters}

The Mo concentrations of springs and surface waters of the Strengbach catchment range from 0.01 to $0.29 \mathrm{nmol}$ (Table 1), 5 to 50 times lower than small rivers from the small Entlebuch catchment, Switzerland (0.53-2.95 nmol Neubert et al., 2011) and the "pre-anthropogenic" estimated concentration of average global dissolved riverine Mo has been estimated by Martin and Meybeck (1979) as $5 \mathrm{nmol}$. More recently, Miller et al. (2011) published a world river average Mo concentration of $8.0 \mathrm{nmol} \mathrm{Mo} \mathrm{kg}{ }^{-1}$, based on 38 rivers equivalent to $37 \%$ of total global water discharge. Although Mo concentrations are unusually low, the Mo isotope compositions of springs and surface waters of the Strengbach catchment (0.69-1.42 \%o, Fig. 2) are in the 'normal' range when compared to the dissolved riverine $\delta^{98 / 95}$ Mo data of Neubert et al. (2011; $0.14-1.60 \%$ ) and Archer and Vance (2008; 0.2\%o to 2.3\%o) at an average of $0.7 \%$. The Sr and Mo isotope signatures from the water analyses presented here (Fig. 9; Table 1). show a clear (non-linear) trend with outlier $(\mathrm{BH})$.

Qualitatively it can be stated that $\delta^{98 / 95} \mathrm{Mo}$ ratios increase with increasing $\mathrm{Cl}^{-}$and $\mathrm{SO}_{4}{ }^{2-}$, (Figs.: 10 and 11), with spring $\mathrm{BH}$ being again an outlier in figure 10 .

Chlorine is deposited globally via marine aerosol, and thus it is taken as proxy for this source (Adriaens et al., 2013). Marine aerosol forms in different ways, resulting in salt particles of different size, totaling around 10-30 Pg of seasalt in aerosols each year (Brimblecombe, 2003). Pupier et al. (2016) studied an experimental beech forest located near Montiers-surSaulx, NE France $(<200 \mathrm{~km}$ west of the Strengbach catchment) and concluded that the observed $\mathrm{Cl}$ concentrations dominantly result from marine aerosols. Already Junge and Werby (1958) monitored $\mathrm{Cl}, \mathrm{Na}, \mathrm{K}, \mathrm{Ca}$ and $\mathrm{SO}_{4}{ }^{2-}$ concentrations in rainwater across the United States and noted a significant influence of marine aerosol as far as $800 \mathrm{~km}$ from the coast. The Strengbach catchment is less than $500 \mathrm{~km}$ from the Channel in the north or the Mediterranean in the south, and less than $700 \mathrm{~km}$ from the Atlantic in the west (i.e. the prevalent wind direction). An influence of marine seasalt on the precipitation is thus plausible. In effect, Probst et al. (2000) described an airborne contribution to the Strengbach catchment that carries the $\mathrm{Sr}$ isotope signature of seawater. The marine contribution to the rain composition can be calculated using the enrichment factor (EF) of element $\mathrm{i}$ according to the 
formula: $\mathrm{EFi}=(\mathrm{Xi} / \mathrm{Na})_{\text {rain }} /(\mathrm{Xi} / \mathrm{Na})_{\text {seawater }}$ where $\mathrm{Xi}$ is the concentration and $\mathrm{Na}$ is considered as a sea salt tracer (Singh et al., 2007; Laouli et al., 2012). In the Strengbach catchment, the average $\mathrm{EF}$ was 1.1 and 24 for $\mathrm{Cl}$ and $\mathrm{SO}_{4}{ }^{2-}$, respectively (Table 4), during the sampling period (2009-2010), illustrating that a large part of sulfate has a non-marine origin (Migliavacca et al., 2005). The time series of rain data in Table 4 with $\mathrm{EF}$ of $\mathrm{Cl}^{-}$and $\mathrm{SO}_{4}{ }^{2-}$ indicates that the marine contribution to the precipitation in the Strengbach catchment is quite constant as reflected by $\mathrm{Na}$ and $\mathrm{Cl}$ concentration. In contrast $\mathrm{SO}_{4}{ }^{2-}$ decreases over time.

$\mathrm{SO}_{4}{ }^{2-}$ has additional, significant non-marine sources as oxidative sulfide weathering and acid rain from anthropogenic $\mathrm{SO}_{4}{ }^{2-}$ emissions. Oxidative sulfide weathering was shown to result in a correlation of $\delta^{98 / 95} \mathrm{Mo}$ with $\mathrm{SO}_{4}{ }^{2-}$ in surface waters (Neubert et al., 2011, Voegelin et al., 2012). This correlation is also observed in our data (Fig. 11). However, in the Strengbach catchment, sulfides where not present in surface granites. Only some small sulfide grains (pyrite, arsenopyrite and $\mathrm{CuS}$ ) were observed in association with ankerite in fractures from northern slope granites. Pierret et al. (2014) proposed that the different geochemical and isotope (i.e. Sr and $\mathrm{U}$ ) signatures of the waters from the single springs from the Strengbach catchment are controlled by different and independent water pathways in fractured granite. Thus, the linear relation between $\delta^{98 / 95} \mathrm{Mo}$ and $\mathrm{SO}_{4}{ }^{2-}$ concentration can be explained by a variable contribution of sulfide dissolution, representing one mixing endmember. The second endmember can be atmospheric with sulfate at least partly reflecting anthropogenic sources (Smith et al., 2001, 2011; Sudalma et al., 2015). In contrast to Mo isotope compositions, Mo concentrations, do not correlate with $\mathrm{SO}_{4}{ }^{2-}$ concentrations (Fig. 12). As noted by Pierret et al (2014), dissolution/precipitation processes of secondary minerals also significantly affect elemental concentrations of the individual source waters.

Atmospheric pollution in open field bulk precipitation is indicated by $\mathrm{NH}_{4}, \mathrm{NO}_{3}$ and $\mathrm{SO}_{4}{ }^{2-}$ (Probst et al., 2000). Mo isotope compositions from industrial contaminates are extremely limited. However, findings of Lane at al. (2003) and Chappaz et al., (2012) point to a predominance of values similar to continental crust and thus, similar to the Strengbach bedrock. Thus anthropogenic Mo may represent a Mo source to the Strengbach catchment with a $\delta^{98 / 95} \mathrm{Mo}$ value similar to bedrock, but with a different [Mo]/ $\mathrm{SO}_{4}{ }^{2-}$.

\subsection{Bedrock}

Whole-rock analyses of six unweathered (but more or less hydrothermally altered) rocks and two weathered rims, as well as strongly weathered material collected at the outlet from the 
Strengbach catchment (Fig. 3) also have a low Mo concentrations compared to similar rocks from other regions and the global average. The Mo concentrations of the 52 Palaeozoic granitic rocks reported by Yang et al. (2017; A-, I- and S-type) from SE Australia (Lachlan Fold Belt and New England Batholith), and the Southern Uplands of Scotland (Loch Doon, Criffell, and Fleet plutons) vary from $0.1 \mathrm{ppm}$ to $8.1 \mathrm{ppm}$ with 48 granites falling into the narrower range of 0.4 to $2.4 \mathrm{ppm}$. The average of $1.1 \mathrm{ppm}$ is consistent with estimates for average continental crust (Rudnick and Gao, 2003). Thus, Mo concentrations of the granites from the Strengbach area (0.12-0.35 ppm, Table 5) are about an order of magnitude lower, probably due to prior fluid Mo removal during magmatic hydrothermal fluid saturation (KD(Mo) $)_{\text {fluid/melt }}$ c. 10 Audédat \& Pettke, 2003). Moreover, minerals in these rocks analyzed by LA-ICP-MS are all below $0.2 \mathrm{ppm}$ with the only exception of oxyhdroxides, which are $>1$ ppm (Table 6). We thus propose, that the low Mo concentrations in the Strengbach waters (in particular springs) mirror the low Mo concentrations in the bedrock. All analyzed rocks have $\delta^{98 / 95}$ Mo between $(0.1$ to $0.5 \%$ ). For samples HP2 (aplitic granite) and RH-1R (granite), both the weathered outer part and the fresh inner part were sampled. No resolvable difference was observed for Mo concentration or $\delta^{98 / 95} \mathrm{Mo}$. Also, the total averages of all weathered ([Mo] $=$ $\left.0.18 \mathrm{ppm}, \delta^{98 / 95} \mathrm{Mo}=0.22 \pm 0.13 \% 2 \sigma\right)$ and fresh samples $\left([\mathrm{Mo}]=0.21 \mathrm{ppm}, \delta^{98 / 95} \mathrm{Mo}=\right.$ $0.24 \pm 0.09 \% 2 \sigma$ ) do not differ significantly. These Mo isotope ratios are typical for continental crust (Voegelin et al., 2014). To address the debate regarding the $\delta^{98 / 95} \mathrm{Mo}$ variability of the continental crust these authors studied high temperature Mo isotope fractionation in a volcano-plutonic system (Kos, Aegean Arc, Greece). These authors determined an average continental $\delta^{98 / 95}$ Mo of +0.3 to $+0.4 \%$ based on their results and previously published data.

\subsection{Foliage, litter and humus}

Mo is taken up by the root network of trees, and incorporated into the organic matter. In the leaf litter layer, Mo forms strong complexes with tannins and humins (Wichard et al., 2009). However, as the biological Mo cycle is not completely isolated in nature, the probable loss of a minor fraction of organic bound Mo needs to be balanced by an Mo flux from surface waters or groundwater, in the reasonable assumption that biomass is in steady state. In experimental setups (Wasylenki et al., 2008; Zerkle et al., 2011) biological uptake from abiogenic Mo sources was found to disproportionate Mo isotopes between an isotopically light organic matter and isotopically heavier residual nutrient liquid. The bacterial Mo isotope 
fractionation was estimated to range between $\Delta^{98 / 95} \mathrm{Mo}_{\text {cell-solution }}=-0.2 \%$ to $-1.0 \%$. It has not yet been quantified in soils because the mass balance between organic bound and abiogenic Mo sources is unknown. However the low $\Delta^{98 / 95} \mathrm{Mo}_{\text {cell-solution, }}$ precludes biological Mo isotope fractionation as a significant component of the $\Delta^{98 / 95}$ Mo between soils and waters in the Strengbach catchment.

\subsection{First order models}

Assuming disproportionation between isotopically light soils and isotopically heavy waters requires an input with an intermediate Mo isotopic composition, in contrast, the Strengbach catchment has bedrock with a lighter Mo isotopic composition than soil or water. Thus, catchment outcrop weathering alone cannot explain riverine $\delta^{98 / 95}$ Mo because the median of granitic bedrocks $\left(\delta^{98 / 95} \mathrm{Mo}_{\mathrm{G}}=0.2 \%\right.$ ) is significantly lower than the median of stream and spring waters $\left(\delta^{98 / 95} \mathrm{Mo}_{\mathrm{W}}=1.1 \%\right)$ and also lower than soil samples, saprolite and organics (Tables 2 a,b and 3). The isotopically heavy stream waters thus require either a "hidden sink" of isotopically light Mo in the catchment, or a heretofore unrecognized, additional "heavy source".

Even though the processes and observations discussed on a plot scale are all significant for local geochemical signatures, Pierret et al. (2014) concluded that the physico-chemical processes in soil do not dominate the chemical balance of waters in the Strengbach catchment. King et al. (2018) hypothesized that Mo adsorption onto organic matter also significantly influences Mo fluxes to the oceans, in order to explain why the global riverine Mo flux appears to be isotopically heavy (Archer and Vance, 2008). However, King et al. (2018) also admit that Mo isotope compositions of organic matter within catchments are strongly influenced by Mo from atmospheric inputs. The relative proportions of these two effects and their influences on the total Mo output from the catchment remained unconstrained. Any global Mo isotope based model that reconstructs the redox history of the atmosphere and hydrosphere, however, is only as good as the assumption on the $\delta^{98 / 95}$ Mo of the continental runoff. This in turn, can only be approached/improved if we understand the recent Mo cycle and related processes.

A simple calculation can be used to evaluate the expected effect of organic matter on the outflow of a catchment. The total volume of organic upper rich soil can be approximated by its average depth $(20 \mathrm{~cm})$ multiplied by the catchment surface area. Given the measured Mo concentrations in soil and outlet as well as the outgoing Mo flux, the total amount of Mo 
present in organic rich soils can be compared to the total annual outgoing flux of dissolved Mo. Using the parameters given in Table 7, the total amount of Mo in organic soils is calculated to be equal to ca. 20 years of outflow. To maintain Mo disequilibrium in the catchment between total input and total output by assuming permanent retention of light Mo isotopes in soils, the soil volume would have to be doubled every 20 years irrespective of the Mo source involved. Failing this large increase, Mo uptake and release would reach steady state in the soil reservoir. For the case of the Strengbach, this implies that the total input has to be $\delta^{98 / 95} \mathrm{Mo}=1.1 \%$. Extending the "light Mo sink" into the deep soil (by postulating a significant additional Mo retention by clays) only increases the time needed to reach steady state, but not its ultimate achievement. Removing the "light Mo sink" via insoluble organic particulate loads, does not solve the paradox of Mo in bedrock being isotopically lighter than both soil and waters. The same accounts for "light Mo" removal via suspended loads. Under normal erosion the contribution of suspended load to the total removal of Mo is negligibly small in the Strengbach catchment. During storm events larger amounts of erosion products leave the catchment. A coarser-grained fraction of this material trapped at the catchments outlet after intense thunderstorms yields $\delta^{98 / 95} \mathrm{Mo}=0.43 \%$ (Table 5). Finer fractions were not trapped, but all fine-grained materials in the soils have $\delta^{98 / 95}$ Mo values above bedrock. It is not plausible to assume a significant drain of particulate Mo with isotopic composition below any potential source component measured in the catchment, including bedrock.

As a consequence it is necessary to explore the possibility of an additional isotopically heavy Mo input. Such an additional isotopically heavy Mo input could be provided by a marine component in precipitations. Probst et al. (2000) described an airborne contribution to the catchment that retains the $\mathrm{Sr}$ isotope signature of seawater. These authors reported that ca. $50 \%$ of dissolved $\mathrm{Sr}$ in stream water was atmospherically derived. This value was calculated based on throughfall (which contains 5-10 times more Sr than open field precipitation) as representative of bulk atmospheric input because $90 \%$ of the area is covered by forest. The total mass of airborne input could be affected by dust derived from local continental sources with high ${ }^{87} \mathrm{Sr} /{ }^{86} \mathrm{Sr}$ (such as loess in the nearby Alsace plain). However, the ${ }^{87} \mathrm{Sr} /{ }^{86} \mathrm{Sr}$ signature points to an airborne source compatible with seasalt.

The marine aerosol hypothesis is further supported by reports of marine aerosols as prominent sources of atmospheric Mo, besides continental dust, volcanic fog and fuel combustion (Marks et al., 2015; Mather et al., 2012; Sansone et al., 2002; Tsukuda et al., 2005). Dust from the application of phosphate fertilizer of marine origin is another potential 
anthropogenic source of Mo and Sr with seawater signatures (see below). Along these lines, significant atmospheric input of Mo to soils is reported by Siebert et al. (2015) and King et al. (2016). King et al. (2016) found up to $+139 \%$ net accumulation of Mo across Hawaiian soils, which is positively correlated with increasing mean annual precipitation. Also, $\delta^{98 / 95} \mathrm{Mo}$ values were lowest at dry sites and increased with increasing precipitation. Mo isotope ratios in local rainwater were $\delta^{98 / 95} \mathrm{Mo}=+1.36 \%$ on average. The conclusion of King et al. (2016) was that in Hawaiian soils, Mo is substantially augmented by additions from precipitation, volcanic fog, and potentially anthropogenic inputs. Moreover, Marks et al. (2015) concluded that atmospheric input may be a significant source of Mo to forest ecosystems. Thus, atmospheric input with seawater-like $\mathrm{Sr}$ and Mo isotope compositions must be taken into account in the quest to find additional Mo influx to sources for the Mo in the Strengbach catchment. Based on isotope dilution concentration measurements (Table 1), the dissolved Mo concentrations at the outlet in autumn 2009 and autumn 2010 were 0.011 and 0.005 ppb, respectively. Further the streamlet samples RAZS $(\mathrm{H} 09=0.009 \mathrm{ppb}, \mathrm{H} 10=0.005 \mathrm{ppb})$ or the average of all dissolved load spring and outlet results $(0.008 \mathrm{ppb})$ are all similar. The multiyear average water outflow is $20 \mathrm{~L} / \mathrm{s}$. In a near steady state situation of the hydrological system, the influx (precipitation) should be of the same order. The balance is achieved when taking into account loss due to evapotranspiration (precipitation: $1400 \mathrm{~mm} / \mathrm{a}$ or $35 \mathrm{~L} / \mathrm{s}$; outflow equals $800 \mathrm{~mm} / \mathrm{a}$ or $20 \mathrm{~L} / \mathrm{s}$ ). The question than becomes, what percentage of the total Mo outflux corresponds to the atmospheric influx. Precise Mo concentration data of precipitation are scarce. We analyzed one open field precipitation and measured $[\mathrm{Mo}]=0.001$ $\mathrm{ppb}$ (Table 1). In order to substantiate this result, we took the available $\mathrm{Sr}$ concentration average (Pierret et al., 2014) and assumed a seawater Sr/Mo ratio to calculate [Mo]. The result is also $0.001 \mathrm{ppb}$. Thus we feel confident using this concentration as a first order approach: As $0.001 \mathrm{ppb} \mathrm{Mo} * 35 \mathrm{~L} / \mathrm{s}$ is about $20 \%$ of $0.008 \mathrm{ppb}$ Mo $* 20 \mathrm{~L} / \mathrm{s}$ about one fifth of the Mo in the dissolved load can be from precipitation, without additional input from dry deposits (see Table 7 for model parameters).

\subsection{Mo and $\mathrm{Sr}$ isotope models}

Heavy element isotope ratio diagrams are excellent for identifying mixing endmembers in surface processes, as their 'source signature' is not affected by dilution or evaporation. The radiogenic ${ }^{87} \mathrm{Sr} /{ }^{86} \mathrm{Sr}$ ratio (as long as it is normalized to the fixed ${ }^{86} \mathrm{Sr} /{ }^{88} \mathrm{Sr}$ ratio of 0.1194 ) is not even subject to isotope fractionation problems during sorption or desorption, processes that might affect $\delta^{98 / 95} \mathrm{Mo}$. In the following section, we evaluate if a simple two-component 
mixing model with rock weathering and marine aerosol as its two endmembers can successfully describe the ${ }^{87} \mathrm{Sr} /{ }^{86} \mathrm{Sr}$ and $\delta^{98 / 95} \mathrm{Mo}$ of the dissolved loads of the Strengbach catchment. As a first step, the endmembers have to be constrained as closely as possible.

Seaspray/Marine endmember: Both, Sr and Mo, with their long residence time in the open ocean (Sr: 2.4 Ma, Ravizza and Zachos, 2003; Mo: 450 ka, Miller et al. 2011; 800 ka, Collier, 1985; Sohrin et al., 1987; Firdaus et al., 2008), have constant isotope compositions and salinity normalized concentrations in the modern open ocean (Table 8). Thus, if sea spray is a significant source to the Strengbach system in terms of Mo and Sr, seawater isotope composition should be used $\left(\delta^{98 / 95} \mathrm{Mo}=2.3\right.$, Nakagawa et al., $2012 ;{ }^{87} \mathrm{Sr} /{ }^{86} \mathrm{Sr}=0.70917$; McArthur et al., 2006; Krabbenhöft et al., 2009; see Table 8 for details).

Weathering endmember: Unweathered bedrock samples from the Strengbach catchment area are scarce, as are Sr isotope ratios of such material. Probst et al. (2000) report one ${ }^{87} \mathrm{Sr} /{ }^{86} \mathrm{Sr}$ value of $0.83838 \pm 1$ from a bedrock granite in the southern part of the catchment. Other granite whole rocks (Data Base Strengbach) range from 0.75950 to $0.84492 \pm 2$ and $1.86091 \pm 2$ for one strongly hydrothermally altered granite.

However, Sr isotope compositions of bulk bedrock might not provide an adequate weathering endmember because the different weathering rates of individual minerals control the isotope budget of weathering solutions, particularly in early, pre-steady state weathering stages (Clow et al., 1997). Another approach in identifying weathering endmember signatures utilizes laboratory leaching. This, however, does not necessarily reflect field conditions. In particular, the application of organic acids (e.g., Wickman and Jacks, 1992) mainly reflects conditions of the upper layers of the soils whereas bedrock weathering is mainly an interaction between rock and mineral acid. Consequently, modeling the isotope ratios of the weathering endmember to account for the specific dissolution and volumetric abundance of each mineral has so far been preferred (Probst et al., 2000). Simulating the interaction between the minerals of the bedrock granite with acid solutions (open field precipitation, throughfall or soil solution) generated a ${ }^{87} \mathrm{Sr} /{ }^{86} \mathrm{Sr}$ ratio of the potential bedrock weathering endmember of 0.736 to 0.742 . However, formation of the weathering solution is of course more complex than just primary mineral dissolution and may include formation and alteration of secondary mineral phases like clays, that incorporate apatite-derived Sr during their formation (Pierret et al., 2014). Thus a plausible alternative is to select the highest ${ }^{87} \mathrm{Sr} /{ }^{86} \mathrm{Sr}$ value in the Strengbach dissolved loads and the corresponding concentration, as this is the observed value of 
dissolved load that is the farthest away from the other assumed endmember, seawater. It represents the best approximation of indigenous $\mathrm{Sr}$, minimally imparted by marine aerosol.

The $\delta^{98 / 95}$ Mo and Mo concentrations of the weathering endmember are the least constrained input parameters. The models discussed below use three approaches. The first Model uses measured $\mathrm{Sr}$ and Mo isotope ratios and concentrations from the sample showing the least potential marine aerosol influence (i.e. with low $\delta^{98 / 95} \mathrm{Mo}$, lowest Mo concentration, and highest ${ }^{87} \mathrm{Sr} /{ }^{86} \mathrm{Sr}$ (RUZS)). This approach reduces the number of assumptions, but the sample $\mathrm{Sr}$ and Mo isotope ratios and concentrations do not represent the ultimate weathering endmember. (2) $\mathrm{Sr}$ data are taken from spring $\mathrm{SH}$, which has the highest ${ }^{87} \mathrm{Sr} /{ }^{86} \mathrm{Sr}$ in Pierret et al. (2014). Because no measured $\delta^{98 / 95} \mathrm{Mo}$ is available for this sample, it is deduced independently via the $\delta^{98 / 95} \mathrm{Mo}$ vs. $\mathrm{SO}_{4}{ }^{2-}$ correlation (see Fig. 11). The model fit does not depend on the precise Mo concentration, but rather on the Sr/Mo ratio of the sources. (3) ${ }^{87} \mathrm{Sr} /{ }^{86} \mathrm{Sr}$ and $\mathrm{Sr}$ concentration are taken from one modeled weathering endmember from Probst et al. (2000), representing interaction of all minerals of one granite with soil solution. The bedrock $\delta^{98 / 95}$ Mo of 0.23 is used as approximation for the Mo endmember (see Table 5 for details).

The good fit to all models (Figs. 13,14 and 15) indicates that marine aerosol is a significant source of dissolved Mo in this catchment. The most important result is that the catchment outlet lies on the model lines defined by independent constraints. This also validates the assumption of steady state condition, namely that total Mo input equals total output for Mo at the catchment scale. This conclusion is not challenged by the one spring within the catchment, spring BH that is offset relative to all others, most likely due to local Mo-fractionation.

Quantification of the amount of marine aerosol is not straightforward because absolute concentrations of Mo and $\mathrm{Sr}$ are underconstrained. The isotope ratios however allow for calculating $\mathrm{Sr}$ and Mo fractions from seaspray relative to local sources. For the outlet, the relative amount of marine aerosol Mo is $23-44 \%$ and $\mathrm{Sr}$ is $8-42 \%$, depending on the choice of weathering components (Figs. 13,14 and 15 and Table 6). The $\delta^{98 / 95}$ Mo of soils and organic matter are 0.3-0.4 \%o lower than the lowest $\delta^{98 / 95}$ Mo of these springs $(0.63 \%$ ). On the other hand none of these reservoirs is below the bedrock $\delta^{98 / 95}$ Mo range of unweathered granite (0.07-0.5\%o). Also, Mo concentration measurements of minerals by LA-ICP-MS did not identify a single (fresh) mineral with significantly enriched Mo that could cause an erratic $\delta^{98 / 95} \mathrm{Mo}$ in the weathering solution by incongruent weathering. The weathering solution $\delta^{98 / 95}$ Mo can thus be bracketed between $0.2 \%$ and $<0.63 \%$. 
The isotope mass balance calculations indicate a marine aerosol Mo contribution of 23-44\%. The simple mixing model (Table 7) described above indicated a $20 \%$ contribution. The two approaches give consistent results, within the high uncertainties involved. However this does not ultimately exclude further sources such as dust (see below). The main attractiveness of the present model is that it is based on mass balance considerations rather than on an assumption of a permanent isotope bias between input and output of a catchment.

\subsection{Fertilizer and Loess: Alternative sources for airborne contributions:}

In addition to marine aerosol identified here, volcanic exhalations, fixation of aerosols onto atmospheric dust particles, and anthropogenic sources like fertilizer or possibly fuel combustion might all be variably relevant but so far have remained underconstrained. For the Strengbach catchment, two possible aerosol sources may provide significant inputs $\mathrm{Sr}$ and or Mo to the system:

Probst et al. (2000) suggested that dust derived from local crustal sources such as loess in the nearby Alsace plain may account for ${ }^{87} \mathrm{Sr} /{ }^{86} \mathrm{Sr}$ ratios above seawater of open field precipitation of the Strengbach catchment. Theoretically, this source could also provide an input isotopically similar to a continental crust Mo input. Such input would be merged with the mixing lines in the models above, and lie on the 'weathering component'. However, carbonate rich loss is not expected to host significant Mo and sulfur species concentrations, except for possibly fixing aerosol Mo via adsorption on airborne particles. To our knowledge this factor is currently unexplored.

Additional Mo (Charter et al., 1995) and Sr could also be sourced from phosphate fertilizers of anthropogenic origin: Due to the marine origin of the vast majority of commercial phosphate, the Sr and Mo from this source are expected to have marine isotopic compositions. While Mo isotope fractionation during phosphate deposition has remained unexplored, some indication of only limited fractionation in marine phosphate formation is given in Wen et al. (2011).

Given the intense corn culturing along with phosphate fertilization, an airborne marine $\mathrm{Sr}$ and Mo input to the Strengbach catchment is plausible. Mo and Sr isotope compositions in this contribution would merge with the 'marine aerosol' endmember in the above mixing models.

It must be stressed that the relative importance of the various Mo sources and isotopic fractionation controls was made clearer by the exceptionally low Mo content of the bedrock in the Strengbach catchment. However, it is plausible that in catchments with mainly carbonate 
bedrock, that show even lower Mo contents (Voegelin et al., 2009), marine aerosol Mo can represent a prominent contribution to the Mo budget. What has emerged from our observations is that the "heavy source" marine aerosol has a greater importance than an assumed reservoir of light Mo in soils. At present, quantification of the global mass balance of marine aerosol input would be premature. However, the inequality between the permanent effects of a hidden reservoir in soils and those of the heretofore neglected marine aerosol input remains.

\section{Conclusions}

On the plot scale

1) In soils, organic matter is the main parameter that governs Mo concentrations. Apparently, there is an efficient Mo recycling from plants to organic litter to plants. This limits Mo loss from the ecosystem and keeps Mo bioavailable, especially in an environment with very low Mo concentrations in rocks and rivers waters. The Mo isotope composition of topsoils and organic matter is rather homogeneous. Net biological fractionation is again less relevant than differences in the isotope composition of the Mo sources. Organic matter contents are observed to be much more important than $\mathrm{pH}$ or Fe oxyhydroxide abundance for controlling Mo concentration differences in soil.

\section{On the catchment scale}

2) Marine aerosol and rock weathering are both prominent sources of Mo in the Strengbach catchment. Our ${ }^{87} \mathrm{Sr} /{ }^{86} \mathrm{Sr}$ vs. $\delta^{98 / 95} \mathrm{Mo}$ isotope correlation and model calculations indicate a $23 \%$ to $44 \%$ Mo fraction of seawater origin in the dissolved load at the outlet of the Strengbach system. A simple mass balance calculation indicated a contribution of $20 \%$. Both independent approaches thus give consistent and robust estimates. Further sources (e.g. fertilizer dust) cannot be excluded however.

3) Despite the distance to ocean water of $>600 \mathrm{~km}$ along predominantly westerly winds, marine aerosol is identified as an important component to the Strengbach Mo budget and, by inference, to the global Mo cycle.

4) Mass balance calculations are inconsistent with significant differences between $\delta^{98 / 95}$ Mo of input and output to the catchment (e.g. due to a hypothetical long-lasting retention of light Mo isotopes in soils). Therefore, soil formation is most likely not causing permanent isotope shifts in Mo continental runoff. 
5) Successful $\delta^{98 / 95} \mathrm{Mo}$ and ${ }^{87} \mathrm{Sr} /{ }^{86} \mathrm{Sr}$ mixing models imply that the catchment has reached steady state for Mo and Sr. Therefore, the $\delta^{98 / 95}$ Mo of the outflow corresponds to the average input signature. The largest uncertainty is caused by the limited constraints on the Mo isotope composition and concentration of the weathering solution. However, the fact that the models offer a solution for both Mo and $\mathrm{Sr}$ isotope ratios indicate that the assumptions made for the bedrock-weathering component are robust.

6) A prominent fraction of Mo in surface waters of the Strengbach catchment is derived from marine aerosols, even hundreds of km away from the seashore. To date, all global Mo isotope cycling models have assumed a continental runoff value based on inferred average continental crust signatures and/or river water averages, where the latter are taken as representing a weathering product of the former. Our findings imply that future Mo isotope global cycling models need to account for the recoupling of airborne Mo. The exact mass balance of contributing Mo sources to the bulk airborne load, are unknown at present. Additional contributions to the aerosol input (volcanic exhalations, fixation of aerosols onto atmospheric dust particles, and anthropogenic sources) are possible but not evident in case of the Strengbach catchment.

Acknowledgements The authors are particularly grateful to U. Linden for his substantial technical support in the field. Two thoughtful reviews are also gratefully acknowledged. We thank S. Benarioumlil, S. Cotel, P. Friedmann, C. Fourtet, S. Gangloff and R. Boutin for providing technical laboratory assistance and field management. This study was supported by the Swiss National Science Foundation Grant: 200021_126759 to TFN. Some data collection was funded by the Observatoire Hydro-Géochimique de l'Environnement. The OHGE is financially supported by the CNRS/INSU France and Université de Strasbourg. The OHGE is part of the French RBV watershed network (French watershed network) and of the OZCAR research infrastructure (http://www.ozcar-ri.org). 
References

Adriaens, P., Gruden, C., \& McCormick, M. L. (2013). Biogeochemistry of Halogenated Hydrocarbons. In H. D. Holland \& K. K. Turekian (Eds.), Treatise on Geochemistry: Second Edition. (Vol. 11, pp. 511-533). Amsterdam, Elsevier.

Archer, C., \& Vance, D. (2008), The isotopic signature of the global riverine molybdenum flux and anoxia in the ancient oceans. Nature Geoscience, 1(9), 597-600.

Arnold, G. L., Anbar, A. D., Barling, J., \& Lyons, T. W. (2004). Molybdenum isotope evidence for widespread anoxia in mid-proterozoic oceans. Science, 304(5667), 87-90.

Audétat, A. \& Pettke, T. (2003). The magmatic-hydrothermal evolution of two barren granites: A melt and fluid inclusion study of the Rito del Medio and Canada Pinabete plutons in Northern New Mexico (USA). Geochimica et Cosmochimica Acta, 67(1), 97-122.

Baldwin, G. J., Nägler, T. F., Greber, N. D., Turner, E. C., \& Kamber, B. S. (2013). Mo isotopic composition of the mid-Neoproterozoic ocean: An iron formation perspective. Precambrian Research, 230, 168-178.

Barling, J., Arnold, G. L., \& Anbar, A. D. (2001). Natural mass-dependent variations in the isotopic composition of molybdenum. Earth and Planetary Science Letters, 193(3-4), 447-457.

Bonhomme, M. (1967). Ages radiométriques de quelques granites des Vosges moyennes. Bulletin Serv. Carte Géologique Alsace - Lorraine. 20, 101- 106.

Boutin, R., Montigny, R., \& Thuizat, R. (1995). Chronologie K-Ar et ${ }^{39} \mathrm{Ar} /{ }^{40} \mathrm{Ar}$ du métamorphisme et du magmatisme des Vosges. Comparaison avec les massifs varisques avoisinants et determination de l'âge de la limite Viséen inférieur - viséen supérieur. Géologie de la France, 1, 3-25.

Brimblecombe, P., (2003). The Global Sulfur Cycle. In H. D. Holland K. K. Turekian (Eds.), Treatise on Geochemistry. (Vol. 8, pp. 645-682). Oxford, Pergamon. doi. 10.1016/B0-08-043751-6/08134-2.

Cenki Tok, B., Chabaux, F., Lemarchand, D., Schmitt, A.-D., Pierret, M.-C., Viville, D., Bagard, M.-L., \& Stille, P. (2009). The impact of water-rock interaction and vegetation on calcium isotope fractionation in soil- and stream waters of a small forested catchment (the Strengbach case). Geochimica et Cosmochimica Acta, 73, 2215-2228.

Chappaz, A., Lyons, T. W., Gordon, G. W., \& Anbar A. D. (2012). Isotopic Fingerprints of Anthropogenic Molybdenum in Lake Sediments. Environmental Science \& Technology, 46(20), 10934-10940.

Charter, R. A., Tabatabai, M. A., \& Schafer, J. W. (2008) Arsenic, molybdenum, selenium, and tungsten contents of fertilizers and phosphate rocks. Communications in Soil Science and Plant Analysis, 26, 17-18, 3051-3062, DOI: 10.1080/00103629509369508.

Ciesielski, H., Sterckeman, T., Santerne, M., \& Willery, J. P. (1997). A comparison between three methods for the determination of cation exchange capacity and exchangeable cations in soils. Agronomie, 17, 9-16.

Clow, D.W., Mast, A., Bullen, T.D., \& Turk, J.T. (1997). Strontium 87/Strontium 86 as a tracer of mineral weathering reactions and calcium sources in a an alpine/subalpine watershed, Loch Vale, Colorado. Water Resource Research. 33(6) 1335-1351.

Collier, R. W. (1985) Molybdenum in the Northeast Pacific Ocean. Limnology and Oceanography, 30, 13511354.

Colodner, D., Edmond, J., \& Boyle, E. (1995). Rhenium in the Black Sea: comparison with molybdenum and uranium. Earth and Planetary Science Letters, 131, 1-15.

Czaja, A. D., Johnson, C. M., Roden, E. E., Beard, B. L., Voegelin, A. R., Nägler, T. F., Beukes, N. J., \& Wille, M. (2012). Evidence for free oxygen in the Neoarchean ocean based on coupled iron-molybdenum isotope fractionation. Geochimica et Cosmochimica Acta, 86, 118-137.

Dambrine, E., Carisey, N., Pollier, B., \& Granier, A. (1992a). Effects of drought on the yellowing status and the dynamic of mineral elements in the xylem sap of a declining spruce stand (Picea abies Karst.). Plant Soil, 150, 303-306.

Dambrine, E., Le Goaster, S., \& Ranger, J. (1991). Croissance et nutrition minérale d'un peuplement d'épicéa sur sol pauvre, II Prélève- ment racinaire et transferts internes d'éléments minéraux au cours de la croissance. Acta Oecologica-International Journal of Ecology, 12(6), 791-808.

Dambrine, E., Pollier, B., Poszwa, A., Ranger, J., Probst, A., Viville, D., Biron, P., \& Granier, A. (1992b). Evidence of current soil acidification in spruce (Strengbach catchment, Vosges mountains, North- Eastern France). Water, Air, \& Soil Pollution., 105, 43-52

de Villiers, S. (1999). Seawater strontium and $\mathrm{Sr} / \mathrm{Ca}$ variability in the Atlantic and Pacific oceans. ). Earth and Planetary Science Letters, 171, 623-634. 
Dellwig, O., Beck, M., Lemke, A., Lunau, M., Kolditz, K., Schnetger, B., \& Brumsack, H. J. (2007). Nonconservative behaviour of molybdenum in coastal waters: Coupling geochemical, biological, and sedimentological processes. Geochimica et Cosmochimica Acta, 71(11), 2745-2761.

Dickson, A. J., Gill, B. C., Ruhl, M., Jenkyns, H. C., Porcelli, D., Idiz, E., Lyons, T. W., \& van den Boorn, S. H. J. M. (2017), Molybdenum-isotope chemostratigraphy and paleoceanography of the Toarcian Oceanic Anoxic Event (Early Jurassic). Paleoceanography, 32, 813-829, doi:10.1002/2016PA003048.

Duan, Y., Anbar, A. D., Arnold, G. L., Lyons, T. W., Gordon, G. W., \& Kendall, B. (2010). Molybdenum isotope evidence for mild environmental oxygenation before the Great Oxidation Event. Geochimica et Cosmochimica Acta, 74(23), 6655-6668.

El Gh'Mari, A. (1995). Etude minéralogique, pétrophysique et géochim- ique de la dynamique d'altération d'un granite soumis au dépôts atmosphériques acides (Bassin versant du Strengbach, Vosges, France) mécanismes, bilans et modélisations, PhD. Thesis, University Strasbourg, Strasbourg, p. 202.

Emerson, S. R., \& Huested, S. S. (1991). Ocean anoxia and the concentrations of molybdenum and vanadium in seawater. Marine Chemistry, 34(3-4), 177-196.

Eroglu, S., Schoenberg, R., Wille, M., Beukes, N., \& Taubald, H. (2015). Geochemical stratigraphy, sedimentology, and Mo isotope systematics of the ca. 2.58- 2.50 Ga-old Transvaal Supergroup carbonate platform, South Africa. Precambrian Research, 266, 27-46.

Fichter, J., Turpault, M. P., Dambrine, E., \& Ranger, J. (1998). Mineral evolution of acid forest soils in the Strengbach catchment (Vosges mountains, N-E France). Geoderma, 82(4), 315-340.

Firdaus, M. L., Norisuye, K., Nakagawa, Y., Nakatsuka, S., \& Sohrin, Y. (2008). Dissolved and labile particulate Zr, Hf, Nb, Ta, Mo and W in the western North Pacific Ocean. Journal of Oceanography, 64(2), 247-257.

Geagea, M. L., Stille, P., Gauthier-Lafaye, F., \& Millet, M. (2008). Tracing of industrial aerosol sources in an urban environment using $\mathrm{Pb}, \mathrm{Sr}$, and $\mathrm{Nd}$ isotopes. Environmental Science \& Technology, 42(3), 692-698.

Goldberg, T., Archer, C., Vance, D., \& Poulton, S.W. (2009). Mo isotope fractionation during adsorption to $\mathrm{Fe}$ (oxyhydr)oxides. Geochimica et Cosmochimica Acta 73, 6502-6516.

Greber, N., Siebert, C., Nägler, Th.F., \& Pettke, Th. (2012). $\delta^{98 / 95}$ Mo values and Molybdenum Concentration Data for NIST SRM 610, 612 and 3134: Towards a Common Protocol for Reporting Mo Data. Geostandards and Geoanalytical Research 36, 3, 291-300, doi: 10.1111/j.1751-908X.2012.00160.x

Guillong, M., Meier, D. L., Allan, M. M., Heinrich, C. A., \& Yardley, B. W. D. (2008). SILLS: A MATLABbased program for the reduction of laser ablation ICP-MS data of homogeneous materials and inclusions. In: Sylvester, P (Ed.), Laser ablation ICP-MS in the Earth Sciences: Current practices and outstanding issues. Mineral. Assoc. Can. Short Course Series (Vol. 40, 328-333).

Junge C.E., \& Werby, R.T. (1958). The concentration of chloride, sodium, potassium and sulfate in rain water over the United States. Journal of Meteorology, 15, 417-425.

Kendall, B., Reinhard, C. T., Lyons, T. W., Kaufman, A. J., Poulton, S. W., \& Anbar, A. D. (2010). Pervasive oxygenation along late Archaean ocean margins.Nature Geoscience, 3, 647.

Kendall, B., Gordon, G. W., Poulton, S. W., \& Anbar, A. D. (2011). Molybdenum isotope constraints on the extent of late Paleoproterozoic ocean euxinia. Earth and Planetary Science Letters, 307(3-4), 450-460.

Kendall, B., Creaser, R. A., Gordon, G. W., \& Anbar, A. D. (2009). Re-Os and Mo isotope systematics of black shales from the Middle Proterozoic Velkerri and Wollogorang Formations, McArthur Basin, northern Australia. Geochimica et Cosmochimica Acta, 73(9), 2534-2558.

King, E. K., Thompson, A., Chadwick, O. A., \& Pett-Ridge, J. C. (2016). Molybdenum sources and isotopic composition during early stages of pedogenesis along a basaltic climate transect. Chemical Geology, 445, 54-67.

King, E. K., Perakis, S. S., \&, Pett-Ridge, J. C. (2018). Molybdenum isotope fractionation during adsorption to organic matter. Geochimica et Cosmochimica Acta, 222, 584-598.

Kpomblekou-A, K. \& Tabatabai, M. A. (2008) Metal contents of phosphate rocks. Communications in Soil Science and Plant Analysis, 25:17-18, 2871-2882, DOI: 10.1080/00103629409369231

Krabbenhöft A., Fietzke J., Eisenhauer A., Liebetrau V., Böhm F., \& Vollstaedt H. (2009). Determination of radiogenic and stable strontium isotope ratios $\left({ }^{87} \mathrm{Sr} /{ }^{86} \mathrm{Sr} ; \delta^{88} /{ }^{86} \mathrm{Sr}\right)$ by thermal ionization mass spectrometry applying an ${ }^{87} \mathrm{Sr} /{ }^{84} \mathrm{Sr}$ double spike. Journal of Analytical Atomic Spectrometry, 24, 1267-1271.

Kurzweil, F., Wille, M., Gantert, N., Beukes, N. J., \& Schoenberg, R. (2016). Manganese oxide shuttling in pre-GOE oceans - evidence from molybdenum and iron isotopes. Earth and Planetary Science Letters, 452, 69-78.

Landmann, G., Bonneau, M., Adrian, M., (1987). Le dépérissement du sapin pectiné et de l'épicéa commun dans le massif vosgien est-il en relation avec l'état nutritionnel des peuplements? Rev. For. Fr. 39, 5-11. 
Lane, S., Proemse, B. C., Tennant, A., \& Wieser, M. E. (2013). Concentration measurements and isotopic composition of airborne molybdenum collected in an urban environment. Analytical and Bioanalytical Chemistry, 405(9), 2957-2963.

Laouali, D., Galy-Lacaux, C., Diop, B., Delon, C., Orange, D., Lacaux, J. P., Akpo A., Lavenu F., Gardrat E. and Castera, P., (2012). Long term monitoring of the chemical composition of precipitation and wet deposition fluxes over three Sahelian savannas. Atmospheric Environment, 50, 314-327.

Marks, J. A., Perakis, S. S., King, E. K., \& Pett-Ridge, J. (2015). Soil organic matter regulates molybdenum storage and mobility in forests. Biogeochemistry, 125(2), 167-183.

Martin, J.-M., \& Meybeck, M. (1979). Elemental mass-balance of material carried by major world rivers, Marine Chemistry, 7(3), 173-206.

Mather, T.A., Witt, M.L.I., Pyle, D.M., Quayle, B.M., Aiuppa, A., Bagnato, E., Martin, R.S., Sims, K.W.W., Edmonds, M., Sutton, A.J., \& Ilyinskaya, E., (2012). Halogens and trace metal emissions from the ongoing 2008 summit eruption of Kilauea volcano, Hawai'i. Geochimica et Cosmochimica Acta 83, 292323. doi: 10.1016/j.gca.2011.11.029.

McArthur J. M., Rio, D., Massari, F., Castradori, D., Bailey, T., Thirlwall, M. \& Houghton, S. (2006). A revised Pliocene record for marine- ${ }^{87} \mathrm{Sr} /{ }^{86} \mathrm{Sr}$ used to date an interglacial event recorded in the Cockburn Island Formation, Antarctic Peninsula. Palaeogeography Palaeoclimatology Palaeoecology, 242, 126136.

McManus, J., Nägler, T. F., Siebert, C., Wheat, C. G., \& Hammond, D. E. (2002). Oceanic molybdenum isotope fractionation: Diagenesis and hydrothermal ridge-flank alteration. Geochemistry Geophysics Geosystems, 3(12), 1078, doi:10.1029/2002GC000356.

McManus, J., Berelson, W. M., Severmann, Poulson, S., R. L., Hammond, D. E., Klinkhammer, G. P., \& Holm, C. (2006), Molybdenum and uranium geochemistry in continental margin sediments: Paleoproxy potential. Geochimica et Cosmochimica Acta, 70(18), 4643-4662.

Migliavacca, D., Teixeira, E. C., Wiegand, F., Machado, A. C. M., \& Sanchez, J., (2005). Atmospheric precipitation and chemical composition of an urban site, Guaiba hydrographic basin, Brazil. Atmospheric Environment, 39(10), 1829-1844.

Miller, C. A., Peucker-Ehrenbrink, B., Walker, B. D., \& Marcantonio, F. (2011). Re-assessing the surface cycling of molybdenum and rhenium. Geochimica et Cosmochimica Acta, 75(22), 7146-7179.

Morford, J. L., \& Emerson, S. R. (1999). The geochemistry of redoxsensitive trace metals in sediments, Geochimica et Cosmochimica Acta, 63, 1735-1750.

Nägler, T. F., Anbar, A. D., Archer, C., Goldberg, T., Gordon, G. W., Greber, N. D., Siebert, C., Sohrin, Y., \& Vance, D. (2014). Proposal for an International Molybdenum Isotope Measurement Standard and Data Representation. Geostandards and Geoanalytical Research, 38(2), 149-151.

Nakagawa, Y., Takano, S., Firdaus, M. L., Norisuye, K., Hirata, T., Vance, D., \& Sohrin, Y. (2012). The molybdenum isotopic composition of the modern ocean. Geochemical Journal, 46(2), 131-141.

Neubert, N., Heri, A. R., Voegelin, A. R., Nägler, T. F., Schlunegger, F., \& Villa, I. M. (2011). The molybdenum isotopic composition in river water: Constraints from small catchments. Earth and Planetary Science Letters, 304(1-2), 180-190.

Pearce, C. R., Burton, K. W., Pogge von Strandmann, P. A. E., James, R. H., \& Gislason, S. R. (2010a). Molybdenum isotope behaviour accompanying weathering and riverine transport in a basaltic terrain. Earth and Planetary Science Letters, 295(1-2), 104-114.

Pearce, C. R., Coe, A. L., \& Cohen, A. S. (2010b). Seawater redox variations during the deposition of the Kimmeridge Clay Formation, United Kingdom (Upper Jurassic): Evidence from molybdenum isotopes and trace metal ratios. Paleoceanography, 25, PA4213.

Pearce, C. R., Cohen, A. S., Coe, A. L., \& Burton, K. W. (2008). Molybdenum isotope evidence for global ocean anoxia coupled with perturbations to the carbon cycle during the Early Jurassic. Geology, 36(3), 231-234.

Pettke, T., Oberli, F., Audetat, A., Guillong, M., Simon, A. C., Hanley, J. J., \& Klemm, L. M., (2012). Recent developments in element concentration and isotope ratio analysis of individual fluid inclusions by laser ablation single and multiple collector ICP-MS. Ore Geology Reviews 44, 10-38.

Pierret, M. C., Stille, P., Prunier, J., Viville, D., \& Chabaux, F. (2014). Chemical and U-Sr isotopic variations in stream and source waters of the Strengbach watershed (Vosges mountains, France). Hydrology and Earth System Sciences, 18(10), 3969-3985.

Pierret, M.C., Viville, D., Dambrine, E., Cotel, S., Probst, A., (submitted). Long-term record of open field precipitation and throughfalls in a medium altitude forested environment (Strengbach catcment - NE France): Response to atmospheric pollution trend. Science of the Total Environment. 
Pierret, M.C., Cotel, S., Ackerer, P., Beaulieu, Emilie, Benarioumlil, S., Boucher, M., Boutin, R., François Chabaux, F., Dambrine, E., Delay, F., Fourtet, C., Friedmann, P., Fritz, B. Gangloff, S., Girard, J-F., Legtchenko, A., Viville, D., Weill, S. \& Probst, A.(accepted). The Strengbach Catchment: a multidisciplinary environmental sentry for 30 years. Vadose Zone Journal.

Probst, A., A. El Gh'Mari, D. Aubert, B. Fritz, and R. McNutt (2000), Strontium as a tracer of weathering processes in a silicate catchment polluted by acid atmospheric inputs, Strengbach, France, Chem. Geol., 170, 203-219.

Probst, A., Dambrine, E., Viville, D., \& Fritz, B. (1990). Influence of acid atmospheric inputs on surface water chemistry and mineral fluxes in a declining spruce stand within a small granitic catchment (Vosges massif - France). Journal of Hydrology, 116, 101-124, 1990.

Probst, A., Fritz, B., \& Stille, P. (1992b). Consequence of acid deposition on natural weathering processes: field studies and modelling. In Y. K. Kharaka \& , A. S.Maest (Eds.), Water Rock Interaction (pp. 581584)., Rotterdam: Balkema.

Probst, A., Viville, D., Fritz, B., Ambroise, B., \& Dambrine, E. (1992a). Hydrochemical budgets of a small forested catchment exposed to acid deposition : the Strengbach catchment case study (Vosges massif, France). Water Air Soil. Pollut., 62, 337-347.

Prunier, J., Chabaux, F., Stille, P., Gangloff, S., Pierret, M.C., Viville D. \& Aubert, A., (2016). Geochemical and isotopic (Sr, U) monitoring of soil solutions from the Strengbach catchment (Vosges mountains, France): Evidence for recent weathering evolution. Chemical Geology 417, 289-305

Pupier, J., Benedetti, L. , Bouchez, Bourlès, D., Leclerc E., Thiry, Y., \& Guillou, V. (2016). Monthly record of the $\mathrm{Cl}$ and ${ }^{36} \mathrm{Cl}$ fallout rates in a deciduous forest ecosystem in NE France in 2012 and 2013. Quaternary Geochronology, 35, 26-35.

Ravizza, G. E. \& Zachos, J. C. (2003). Records of Cenozoic Ocean Chemistry In H. D. Holland K. K. Turekian (Eds.), Treatise on Geochemistry. (Vol. 6, pp. 551-581). Oxford, Pergamon.

Rudnick, R. L. \& Gao, S. (2003). Composition of the Continental Crust. In H. D. Holland K. K. Turekian (Eds.), Treatise on Geochemistry. (Vo. 3, pp 1-64) Amsterdam Elsevier.

Sansone, F.J., Benitez-Nelson, C.R., Resing, J.A., DeCarlo, E.H., Vink, S.M., Heath, J.A.,Huebert, B.J., (2002). Geochemistry of atmospheric aerosols generated from lava- seawater interactions. Geophysical Research Letters, 29, 2-5. doi: 10.1029/2001GL013882.

Siebert, C., Pett-Ridge, J. C., Opfergelt, S., Guicharnaud, R. A., Halliday, A. N., \& Burton, K. W. (2015). Molybdenum isotope fractionation in soils: Influence of redox conditions, organic matter, and atmospheric inputs. Geochimica et Cosmochimica Acta, 162, 1-24.

Siebert, C., Kramers, J. D., Meisel, T., Morel, P., \& Nägler, T. F. (2005). PGE, Re-Os, and Mo isotope systematics in Archean and early Proterozoic sedimentary systems as proxies for redox conditions of the early Earth. Geochimica et Cosmochimica Acta, 69(7), 1787-1801.

Siebert, C., Nägler, T. F., \& Kramers, J. D. (2001). Determination of molybdenum isotope fractionation by double-spike multicollector inductively coupled plasma mass spectrometry, Geochemistry Geophysics Geosystems, 2, art. no.-2000GC000124.

Siebert, C., Nägler, T. F., von Blanckenburg, F., \& Kramers, J. D. (2003), Molybdenum isotope records as a potential new proxy for paleoceanography, Earth and Planetary Science Letters, 211(1-2), 159-171.

Singh, K. P., Singh, V. K., Malik, A., Sharma, N., Murthy, R. C. and Kumar, R., 2007. Hydrochemistry of wet atmospheric precipitation over an urban area in Northern Indo-Gangetic Plains. Environmental monitoring and assessment, 131(1-3), 237.

Smith, S. J., van Aardenne, J., Klimont, Z., Andres, R., Volke, A. C. \& Delgado Arias, S. (2011). Anthropogenic sulfur dioxide emissions: 1850-2005. Atmos. Chem. Phys., 11, 1101-16

Smith S.J., Pitcher H. \& Wigley T.M., (2001). Global and regional anthropogenic sulfure dioxides emissions. Global planet Change 29, 99-119.

Sohrin, Y., Isshiki, K., Kuwamoto, T. \& Nakayama, E. (1987). Tungsten in north Pacific waters. Marine Chemistry, 22, 95-103.

Stiefel, E. L. (2002). The biogeochemistry of molybdenum and tungsten. In A. Sigel \& H. Sigel (Eds.), Molybdenum and Tungsten: Their Roles in Biological Processes, Vol 39, pp. 1-29. Boca Raton FL, CRC Press.

Stille, P., Pourcelot, L., Granet, M., Pierret, M. C., Gueguen, F., Perrone, T., Morvan, G., \& Chabaux, F. (2011). Deposition and migration of atmospheric $\mathrm{Pb}$ in soils from a forested silicate catchment today and in the past (Strengbach case): Evidence from $\mathrm{Pb}-210$ activities and $\mathrm{Pb}$ isotope ratios, Chemical Geology, 289(1-2), 140-153. 
Sudalma, S., Purwanto, P., \& Santoso, L. W., (2015). The effect of SO2 and NO2 from transportation and stationary emissions sources to SO42- and NO3- in rain water in Semarang. Procedia Environmental Sciences, 23, 247-252.

Tsukuda, S., Sugiyama, M., Harita, Y., \& Nishimura, K., (2005). Atmospheric bulk deposition of soluble phosphorus in Ashiu Experimental Forest, Central Japan: source apportionment and sample contamination problem. Atmos. Environ. 39, 823-836. doi: 10.1016/j.atmosenv.2004.10.028.

Villa, I.M., Nägler, T.F., \& Voegelin A.R. (2017) Mo isotopic fractionation in Tso Morari lake waters. Paper presented at $32^{\text {nd }}$ Himalaya-Karakorum-Tibet International Workshop, Chinese Academy of Sciences, Kunming, China.

Voegelin, A. R., Nägler, T. F., Samankassou, E., \& Villa, I. M. (2009) Molybdenum isotopic composition of modern and Carboniferous carbonates. Chemical Geology, 265(3-4), 488-498.

Voegelin, A. R., Nägler, T. F., Pettke, T., N. Neubert, N., Steinmann, M., Pourret, O., \& Villa, I. M. (2012). The impact of igneous bedrock weathering on the Mo isotopic composition of stream waters: Natural samples and laboratory experiments. Geochimica et Cosmochimica Acta, 86, 150-165.

Voegelin, A. R., Pettke, T., Greber, N., von Niederhäusern, B. \& Nägler, Th.F. (2014). Magma differentiation fractionates Mo isotope ratios: Evidence from the Kos Plateau Tuff (Aegean Arc). Lithos, 190/191, 440448, doi: 10.1016/j.lithos.2013.12.016

Wang, Z., Ma, J., Li, J., Wei, G., Chen, X., Deng, W., Xie, L., Lu, W., \& Zou, L. (2015). Chemical weathering controls on variations in the molybdenum isotopic composition of river water: evidence from large rivers in China. Chemical Geology, 410, 201-212. doi: 10.1016/j.chemgeo.2015.06.022.

Wasylenki, L. E., Anbar, A. D., Liermann, L. J., Mathur, R., Gordon, G. W., \& Brantley S. L. (2007). Isotope fractionation during microbial metal uptake measured by MC-ICP-MS. Journal of Analytical Atomic Spectrometry 22, 905-910.

Wen, H.J., Carignan, J., Zhang, Y.X., Fan, H.F., Cloquet, C., Liu, S.R., (2011). Molybdenum isotopic records across the Precambrian-Cambrian boundary. Geology 39, 775-778.

Wichard, T., Mishra, B., Myneni, S. C. B., Bellenger, J. P., \& Kraepiel, A. M. L. (2009). Storage and bioavailability of molybdenum in soils increased by organic matter complexation. Nature Geoscience, 2(9), 625-629.

Wickman, T., Jacks, G., 1992. Strontium isotopes in weathering budgeting. . In Y. K. Kharaka \& , A. S. Maest (Eds.), Water Rock Interaction (pp611-614)., Rotterdam: Balkema.

Wille, M., Nägler, T. F., Lehmann, B., Schröder, S., \& Kramers, J. D. (2008). Hydrogen sulphide release to surface waters at the Precambrian/Cambrian boundary. Nature, 453, 767.

Wille, M., Kramers, J. D., Nägler, T. F., Beukes, N. J., Schröder, S., Meisel, T., Lacassie, J. P., \& Voegelin, A. R. (2007). Evidence for a gradual rise of oxygen between 2.6 and $2.5 \mathrm{Ga}$ from Mo isotopes and RePGE signatures in shales. Geochimica et Cosmochimica Acta, 71(10), 2417-2435.

Yang, J., Barling, J., Siebert, C., Fietzke, J., Stephens, E., \& Halliday, A. N. (2017). The molybdenum isotopic compositions of I-, S- and A-type granitic suites. Geochimica et Cosmochimica Acta, 205, 168186.

Zerkle, A.L., Scheiderich, K., Maresca, J.A., Liermann, L.J., \& Brantley, S.L. (2011). Molybdenum isotope fractionation by cyanobacterial assimilation during nitrate utilization and N2 fixation. Geobiology 9, 94106. http://dx.doi.org/10.1111/j.1472-4669.2010.00262.x. 
Table 1

Mo and Sr isotope data and other parameters of the water samples

\begin{tabular}{|c|c|c|c|c|c|c|c|c|c|c|c|c|}
\hline Sample & taken & Type & Cover & $\delta^{98 / 95} \mathrm{Mo}$ & $2 \sigma$ & Mo & Mo & ${ }^{87} \mathrm{Sr} /{ }^{86} \mathrm{Sr}$ & $2 s^{a}$ & $\mathrm{pH}$ & $\mathrm{Cl}^{-}$ & $\mathrm{SO}_{4}{ }^{2-}$ \\
\hline & & & & [\%o] & & [ppb] & [nmol/L] & & & & [mmol/L] & {$[\mathrm{mmol} / \mathrm{L}]$} \\
\hline RS (H09) & Oct-09 & outlet & & - & - & 0.011 & 0.12 & 0.724434 & 0.000064 & 6.80 & 0.049 & 0.054 \\
\hline RAZS (H10) & Oct-10 & stream & & 1.13 & 0.09 & 0.005 & 0.05 & 0.725372 & 0.000057 & & 0.048 & 0.063 \\
\hline RUZS (H09) & Oct-09 & spring & Beech & 0.80 & 0.13 & 0.007 & 0.08 & 0.726051 & 0.000045 & 6.76 & 0.026 & 0.045 \\
\hline CS3 (H09) & Oct-09 & spring & Spruce & - & - & 0.005 & 0.05 & 0.723134 & 0.000058 & 6.35 & 0.055 & 0.058 \\
\hline RH (F10) & May-10 & spring & Spruce & 1.13 & 0.08 & 0.003 & 0.04 & & & & & $0.064^{\mathrm{C}}$ \\
\hline RH3 (H09) & Oct-09 & spring & Spruce & 1.42 & 0.10 & 0.016 & 0.16 & 0.721546 & 0.000047 & 6.35 & 0.053 & 0.070 \\
\hline RH3 (F10) & May-10 & spring & Spruce & 1.37 & 0.07 & 0.003 & 0.03 & 0.723308 & 0.000010 & & $0.052^{b}$ & $0.072^{b}$ \\
\hline
\end{tabular}

Note: $\delta^{98 / 95}$ Mo data are reported as deviation in \%o from a reference material, whereby the NIST SRM 3134 is defined to have $\delta^{98 / 95}$ Mo $=$ $0.25 \%$, following Nägler et al. (2014).

${ }^{\mathrm{a}} 2 \sigma$ error of the mean of the measurement. The long term external reproducibility of standard measurements is better than $0.1 \%$ ( 2 SD)

banions measured in Bern, all other anions measured in Strasbourg. ${ }^{c}$ interpolation from long term trend 
Table $2 a$

Beech experimental plot: Mo isotope data and other parameters of soil

\begin{tabular}{|c|c|c|c|c|c|c|c|c|c|c|c|}
\hline soil profile & & & & & & & & & & & \\
\hline depth & mean & OM & $\mathrm{pH}$ & $\mathrm{C}_{\text {tot }}$ & CEC & $\delta^{98 / 95} \mathrm{Mo}$ & $2 \sigma^{a}$ & Mo & $\mathrm{Ca}_{\mathrm{ex}}{ }^{\mathrm{b}}$ & $\mathrm{Fe}$ & $\mathrm{Mn}$ \\
\hline$[\mathrm{cm}]$ & {$[\mathrm{cm}]$} & [\%] & & [g/100g] & [cmol/kg] & [\%o] & & [ppm] & [g/kg] & [ppm] & [ppm] \\
\hline Humus & 0.0 & & & & & 0.42 & 0.08 & 1.66 & & & \\
\hline $0-5$ & 2.5 & 19.7 & 3.14 & 10.4 & 24.3 & 0.54 & 0.05 & 0.82 & 0.279 & 0.342 & 0.547 \\
\hline $5-8$ & 6.5 & 16.1 & 3.14 & 7.84 & 19.9 & & & & 0.159 & 0.387 & 0.260 \\
\hline $5-10$ & 7.5 & & & & & 0.39 & 0.05 & 0.37 & & & \\
\hline $8-13$ & 10.5 & 10.0 & 3.18 & 4.58 & 14.8 & & & & 0.0555 & 0.942 & 0.108 \\
\hline $10-20$ & 15.0 & & & & & 0.42 & 0.07 & 0.33 & & & \\
\hline $13-20$ & 16.5 & 7.72 & 3.24 & 3.40 & 16.1 & & & & 0.0276 & 1.74 & 0.067 \\
\hline $20-25$ & 22.5 & 8.36 & 3.31 & 3.37 & 16.3 & & & & 0.0188 & 2.29 & 0.078 \\
\hline $25-30$ & 27.5 & 7.88 & 3.40 & 2.91 & 16 & & & & 0.0164 & 1.84 & 0.145 \\
\hline $30-35$ & 32.5 & 6.83 & 3.48 & 2.56 & 14.5 & & & & 0.0113 & 1.38 & 0.179 \\
\hline $30-40$ & 35.0 & & & & & 0.37 & 0.05 & 0.27 & & & \\
\hline $43-48$ & 45.5 & 6.86 & 3.58 & 2.65 & 15.1 & & & & 0.0118 & 0.979 & 0.232 \\
\hline $50-60$ & 55.0 & 6.55 & 3.65 & 2.29 & 14 & 0.35 & 0.05 & 0.27 & 0.00848 & 0.548 & 0.143 \\
\hline $60-65$ & 62.5 & 6.22 & 3.68 & 2.03 & 12.5 & & & & 0.00842 & 0.208 & 0.099 \\
\hline $70-75$ & 72.5 & 4.86 & 3.72 & 1.93 & 10.4 & & & & 0.00692 & 0.245 & 0.065 \\
\hline $70-80$ & 75.0 & & & & & 0.74 & 0.06 & 0.48 & & & \\
\hline $75-80$ & 77.5 & 5.40 & 3.75 & 1.94 & 12.8 & & & & 0.00658 & 0.289 & 0.053 \\
\hline $80-85$ & 82.5 & 6.81 & 3.78 & 2.09 & 12.4 & & & & 0.00688 & 0.531 & 0.031 \\
\hline $85-90$ & 87.5 & 5.39 & 3.80 & 1.79 & 12.1 & & & & 0.00748 & 0.348 & 0.027 \\
\hline $90-100$ & 95.0 & 4.60 & 3.84 & 1.41 & 9.35 & 0.30 & 0.04 & 0.37 & 0.00716 & 0.243 & 0.019 \\
\hline 105-115 & 110.0 & 2.64 & 3.83 & 0.60 & 6.0 & & & & 0.00574 & 0.109 & 0.018 \\
\hline $110-120$ & 115.0 & & & & & 0.26 & 0.05 & 0.45 & & & \\
\hline $115-130$ & 122.5 & 1.82 & 4.17 & 0.31 & 3.87 & & & & 0.0121 & 0.109 & 0.242 \\
\hline 130-145 & 137.5 & 2.05 & 4.18 & 0.33 & 4.52 & & & & 0.0232 & 0.088 & 0.240 \\
\hline
\end{tabular}

Note: OM: organic matter. $\mathrm{C}_{\text {tot: }}$ total Carbon, no significant carbonate $\mathrm{C}$ present. Cation-exchange capacity. Mo measurements are made on equivalent but not identical samples. $\delta^{98 / 95}$ Mo data reported as \%o deviation relative to NIST SRM $3134=0.25 \%$, (Nägler et al., 2014). ${ }^{a} 2 \sigma$ error of the measurement; ${ }^{b} \mathrm{Ca}$ ex: exchangeable $\mathrm{Ca}$ (see methods for details) 
Table $2 b$

Spruce experimental plot: Mo isotope data and other parameters of soil

\begin{tabular}{|c|c|c|c|c|c|c|c|c|c|c|c|c|}
\hline soil profile & & & & & & & & & & & & \\
\hline depth & mean & OM & $\mathrm{pH}$ & $\mathrm{C}_{\text {tot }}$ & CEC & $\delta^{98 / 95} \mathrm{Mo}$ & $2 \sigma^{a}$ & Mo & $\mathrm{Ca}_{\mathrm{ex}}{ }^{\mathrm{b}}$ & $M n_{e x}{ }^{b}$ & $\mathrm{Al}_{\mathrm{ex}}^{\mathrm{b}}$ & $\mathrm{Fe}_{\mathrm{ex}}^{\mathrm{b}}$ \\
\hline$[\mathrm{cm}]$ & {$[\mathrm{cm}]$} & [\%] & & {$[\mathrm{g} / 100 \mathrm{~g}]$} & [cmol/kg] & [\%o] & & [ppm] & {$[\mathrm{g} / \mathrm{kg}]$} & {$[\mathrm{mg} / \mathrm{kg}]$} & {$[\mathrm{mg} / \mathrm{kg}]$} & {$[\mathrm{mg} / \mathrm{kg}]$} \\
\hline 0.0 & 0.0 & 9.86 & 3.30 & 4.66 & 17 & & & & 0.0535 & 23.6 & 1890 & 3400 \\
\hline 0.0 & 0.0 & 28.4 & 3.21 & 14.2 & 33.7 & & & & 0.194 & 71.6 & 1790 & 2430 \\
\hline $3-13$ & 8.0 & 19.8 & & 9.51 & 25.5 & 0.50 & 0.08 & 0.7 & 0.127 & 53.6 & 1770 & 2440 \\
\hline $13-16$ & 14.5 & & & 3.24 & 14.6 & 0.38 & 0.05 & 0.45 & 0.02 & 13.2 & 1860 & 3450 \\
\hline $16-21$ & 18.5 & 5.20 & 3.57 & 1.77 & 12.7 & 0.18 & 0.08 & 0.6 & $<0,02$ & 43.3 & 2040 & 4930 \\
\hline rep & & & & & & 0.20 & 0.04 & 0.6 & & & & \\
\hline $21-30$ & 25.5 & 5.00 & 3.73 & 1.62 & 13.5 & 0.28 & 0.04 & 0.41 & $<0,02$ & 73.1 & 2570 & 5050 \\
\hline $30-40$ & 35.0 & 4.52 & 3.86 & 1.30 & 13.5 & 0.18 & 0.05 & 0.42 & $<0,02$ & 39.5 & 2840 & 5080 \\
\hline rep & & & & & & 0.25 & 0.06 & 0.42 & & & & \\
\hline $40-45$ & 42.5 & 3.99 & 3.92 & 1.06 & 12.3 & 0.28 & 0.05 & 0.42 & $<0,02$ & 31.0 & 2950 & 4790 \\
\hline $45-50$ & 47.5 & 3.90 & 3.94 & 0.91 & 11.4 & 0.37 & 0.04 & 0.41 & $<0,02$ & 29.7 & 3110 & 4980 \\
\hline rep. & & & & & & 0.33 & 0.06 & 0.41 & & & & \\
\hline $50-56$ & 53 & 3.95 & 3.92 & 0.74 & 11.5 & 0.27 & 0.04 & 0.4 & $<0,02$ & 22.0 & 3040 & 4610 \\
\hline $56-61$ & 58.5 & 3.90 & 3.92 & 0.82 & 11.5 & 0.24 & 0.05 & 0.4 & $<0,02$ & 70.1 & 2630 & 4100 \\
\hline $61-67$ & 64 & 3.08 & 3.92 & 0.66 & 10.4 & 0.25 & 0.06 & 0.41 & $<0,02$ & 17.4 & 2720 & 4060 \\
\hline $61-67$ & 64 & 3.08 & 3.92 & 0.66 & & & & & & & & \\
\hline $70-75$ & 72.5 & 3.12 & 4.14 & 0.46 & 10.8 & 0.34 & 0.04 & 0.42 & $<0,02$ & 13.2 & 2740 & 3900 \\
\hline $75-80$ & 77.5 & 3.31 & 4.14 & 0.53 & 9.65 & 0.26 & 0.05 & 0.41 & $<0,02$ & 11.8 & 2880 & 4180 \\
\hline $81-90$ & 84.5 & 3.07 & 4.16 & 0.49 & 10.2 & 0.28 & 0.04 & 0.42 & $<0,02$ & 13.9 & 2950 & 4020 \\
\hline $90-96$ & 93 & 2.90 & 4.15 & 0.44 & 9.75 & 0.32 & 0.04 & 0.39 & $<0,02$ & 12.1 & 2600 & 3460 \\
\hline 96-105 & 100.5 & 2.96 & 4.14 & 0.43 & 9.96 & 0.25 & 0.05 & 0.45 & $<0,02$ & 13.7 & 2960 & 4160 \\
\hline 115-130 & 122.5 & & & 0.51 & & 0.15 & 0.05 & 0.44 & & & & \\
\hline $130-140$ & 135 & & & 0.49 & 8.46 & & & & $<0,02$ & 9.66 & 2920 & 2210 \\
\hline
\end{tabular}

Note: OM: organic matter. $\mathrm{C}_{\text {tot: }}$ total Carbon, no significant carbonate C present. CEC: Cation-exchange capacity. Mo measurements are made on equivalent but not identical samples. rep: second measurement. $\delta^{98 / 95}$ Mo data reported as \%o deviation relative to NIST SRM $3134=0.25 \%$, (Nägler et al., 2014). ${ }^{a} 2 \sigma$ error of the measurement; ${ }^{b} X_{\text {ex: }}$ exchangeable cations (see methods for details) 
Table 3

Mo isotope data of plant parts and litter

\begin{tabular}{cccc}
\hline depth & $\boldsymbol{\delta}^{\mathbf{9 8 / 9 5} \mathbf{M o}}$ & $\mathbf{2 \sigma ^ { \mathbf { a } }}$ & Mo \\
\hline $\begin{array}{c}\text { [cm] } \\
\text { beech plot }\end{array}$ & {$[\% 0]$} & & {$[\mathrm{ppm}]$} \\
$\quad$ root & 0.31 & 0.08 & 0.035 \\
leaf litter & 0.65 & 0.05 & 0.015 \\
& & & \\
spruce plot & & & \\
$\quad$ root & 0.40 & 0.07 & 0.022 \\
needles & 0.51 & 0.10 & 0.020 \\
\hline
\end{tabular}

$\delta^{98 / 95} \mathrm{Mo}$ data are reported as deviation in \%o from a reference material, whereby the NIST SRM 3134 is defined to have $\delta^{98 / 95} \mathrm{Mo}=0.25 \%$, following Nägler et al. (2014). ${ }^{\mathrm{a}} 2 \sigma$ error of the mean of the measurement. 
Table 4

Open field precipitation of selected periods

\begin{tabular}{|c|c|c|c|c|c|c|c|c|c|c|c|}
\hline period & $\mathbf{n}$ & $\mathrm{pH}$ & $\mathrm{Na}^{+}$ & $\mathrm{K}^{+}$ & $\mathrm{Mg}^{2+}$ & $\mathrm{Ca}^{2+}$ & $\mathrm{Cl}^{-}$ & $\mathrm{NO}_{3}{ }^{-}$ & $\mathrm{SO}_{4}{ }^{2-}$ & $\mathrm{EF}_{\mathrm{Cl}}{ }^{\mathrm{a}}$ & $\mathrm{EF}_{\mathrm{SO}{ }^{\mathrm{a}}}$ \\
\hline & & & [mmol/L] & [mmol/L] & [mmol/L] & [mmol/L] & [mmol/L] & [mmol/L] & [mmol/L] & & \\
\hline $1998-92^{b}$ & 156 & 4.75 & 0.014 & 0.007 & 0.003 & 0.009 & 0.018 & 0.032 & 0.023 & 1.1 & 27 \\
\hline $2004-06^{b}$ & 76 & 4.87 & 0.013 & 0.006 & 0.002 & 0.006 & 0.015 & 0.033 & 0.015 & 0.9 & 18 \\
\hline $2009^{b}$ & 25 & 5.11 & 0.010 & 0.004 & 0.004 & 0.009 & 0.011 & 0.028 & 0.012 & 1.0 & 20 \\
\hline $2010^{b}$ & 25 & 5.12 & 0.007 & 0.004 & 0.003 & 0.010 & 0.010 & 0.029 & 0.012 & 1.2 & 28 \\
\hline $2014^{b}$ & 25 & 5.14 & 0.008 & 0.005 & 0.003 & 0.012 & 0.011 & 0.023 & 0.009 & 1.2 & 20 \\
\hline $27 / 9 / 17^{c}$ & 1 & 5.99 & 0.008 & 0.009 & 0.003 & 0.004 & 0.011 & 0.014 & 0.007 & 1.2 & 15 \\
\hline
\end{tabular}

${ }^{a}$ enrichment factor $(E F): E F i=(X i / N a)_{\text {rain }} /(X i / N a)_{\text {seawater }}$ (Singh et al.. 2007; Laouli et al.. 2012. Millero et al.. 2008).

${ }^{\mathrm{b}}$ OHGE data base (http://bdd-ohge.u-strasbg.fr); Probst et al 2000; Pierret et al 2014;

${ }^{c}$ this study. 
Table 5

Molybdenum concentration and isotopic compositions of rocks

\begin{tabular}{|c|c|c|c|c|}
\hline Sample & Sample type & $\mathrm{Mo}^{\mathrm{a}}$ & $\delta^{98 / 95} \mathrm{Mo}$ & $2 \sigma^{b}$ \\
\hline & & [ppm] & {$[\%$ ] } & \\
\hline HP2-F & granitic aplite & 0.131 & & \\
\hline HP2-F & granitic aplite & 0.134 & 0.31 & 0.04 \\
\hline HP2-W & granitic aplite & 0.119 & 0.27 & 0.07 \\
\hline HP2-W & granitic aplite & 0.134 & 0.22 & 0.05 \\
\hline RH-1R-F & granite & 0.140 & 0.07 & 0.05 \\
\hline RH-1R-W & granite & 0.190 & 0.08 & 0.03 \\
\hline RH-1R-W & granite & 0.230 & 0.07 & 0.05 \\
\hline AU2-F & granite & 0.200 & & \\
\hline AU2-F & granite & 0.208 & 0.24 & 0.08 \\
\hline $\begin{array}{l}\text { RS-1R } \\
\text { (outlet) }\end{array}$ & $\begin{array}{c}\text { granitic } \\
\text { gravel }\end{array}$ & 0.140 & & \\
\hline $\begin{array}{l}\text { RS-1Rc } \\
\text { (outlet) }\end{array}$ & $\begin{array}{l}\text { granitic } \\
\text { gravel }\end{array}$ & 0.209 & 0.43 & 0.06 \\
\hline HP1-F & granite & 0.127 & 0.18 & 0.07 \\
\hline R1-RAZS-F & granite & 0.330 & 0.22 & 0.04 \\
\hline R1-RAZS-F & granite & 0.350 & 0.19 & 0.04 \\
\hline GN2-F & gneiss & 0.226 & 0.47 & 0.06 \\
\hline
\end{tabular}

Note. $\mathrm{W}=$ weathered outer part, $\mathrm{F}=$ inner part

${ }^{a}$ Replicates of concentration measurements indicate a pooled standard deviation of 0.04 ppm (2SD)

${ }^{\mathrm{b}}$ Uncertainty given as $2 \sigma$ err of the measurement. The results of the replicates indicate a pooled standard deviation of $0.04 \%$ (2SD)

${ }^{\mathrm{C}}$ Granitic gravel trapped at the catchments outlet after thunderstorms 
Table 6

Average Mo concentrations in magmatic- and weathering phases of rock HP-2

\begin{tabular}{lccc}
\hline \multicolumn{1}{r}{ rock sample HP-2 } & Mo & $\mathbf{n}^{\mathbf{a}}$ & SD $^{\mathbf{b}}$ \\
\hline Quartz & {$[\mu \mathrm{g} / \mathrm{g}]$} & & \\
Plagioclase & $<0.003$ & 3 & \\
Biotite & 0.04 & 1 & \\
K-feldspar & 0.12 & 2 & 0.06 \\
\hline
\end{tabular}

Oxy-hydroxides:

\begin{tabular}{l|lll}
\hline - light beige & 0.10 & 1 & \\
\hline -orange & 0.12 & 2 & 0.01 \\
\hline -dark brown & 0.31 & 2 & 0.10 \\
\hline -dark brown & 5.29 & 1 & \\
\hline
\end{tabular}

rock sample $R H-1 R$

\begin{tabular}{lccc}
\hline strongly weathered Feldspar & $<0.005$ & 1 & \\
Quartz & $<0.003$ & 2 & \\
\hline Biotite & 0.10 & 2 & 0.11
\end{tabular}

Oxy-hydroxides:

\begin{tabular}{llll} 
- light beige & 0.05 & 1 & \\
\hline - light brown & 0.13 & 4 & 0.03 \\
\hline - brown & 0.33 & 1 & \\
\hline - dark brown & 0.91 & 3 & 0.08 \\
\hline
\end{tabular}

Notes.

${ }^{a} \mathrm{n}=$ number of measured spots

b 1 standard deviation where multiple spots are measured 
Table 7

Parameters of first order mass balance calculation of the Mo budget

\begin{tabular}{lcc}
\hline water flux & In & Out \\
\hline & precipitation & outlet $(\mathrm{RS})^{\mathrm{a}}$ \\
\hline Volume/time [mm/a] & 1400 & \\
Vol./t [L/s] & $35^{\mathrm{b}}$ & 20 \\
Mo [ppb] & 0.0011 & 0.008 \\
Mo total [g/a] & 1214 & 5046 \\
& & \\
\hline Inventory & & \\
\hline & soil & OM-rich soil \\
\hline Volume ${ }^{\mathrm{c}}[\mathrm{m} 3]$ & {$[0-100 \mathrm{~cm}]$} & {$[0-20 \mathrm{~cm}]$} \\
Density $^{\mathrm{d}}$ [g/cm3] & 800000 & 160000 \\
Mo [ppm] & 1.6 & 1.0 \\
Mo total [g] & 0.5 & 0.7 \\
\hline
\end{tabular}

Note. Mo from precipitation equals $24 \%$ of total Mo outflux of the catchment.

Assuming all Mo would be exchangeable the mean residence time in soils (inventory divided by flux out) would be 22 a (only $20 \mathrm{~cm}$ of organic soils considered) or $127 \mathrm{a}$ (considering the upper meter). Assuming a smaller fraction of exchangeable Mo reduces these residence times. Steady state would be closely approached within decades, i.e. $\delta^{98 / 95}$ Mo of the input equals $\delta^{98 / 95}$ Mo of the total output, which is measured (RS) as $1.1 \%$.

${ }^{a}$ loss due to evaporation is not relevant for Mo cycle. ${ }^{b}$ calculated from long term average precipitation (1400 mm/a) and surface area. ${ }^{\mathrm{C}}$ calculated based on a catchment surface of $0.8 \mathrm{~km} 2 .{ }^{\mathrm{d}}$ average bulk density based on 'https://de.wikipedia.org/wiki/Lagerungsdichte' last time accessed 22.3.2018 
Table 8

Parameters of mixing models based on Mo and Sr isotope data

\begin{tabular}{|c|c|c|c|c|c|c|}
\hline & ${ }^{87} \mathrm{Sr} /{ }^{86} \mathrm{Sr}$ & $\delta^{98 / 95} \mathrm{Mo}$ & $\mathrm{Sr}$ & Mo & $\mathrm{Sr}_{\mathrm{sw}}{ }^{\mathrm{a}}$ & Mosw ${ }^{a}$ \\
\hline & & & [ppb] & [ppb] & $\%$ & $\%$ \\
\hline \multicolumn{7}{|c|}{ End-Member 1 'seawater / marine aerosol' } \\
\hline (EM1) & $0.70917^{b}$ & $2.30^{c}$ & $7658^{d}$ & $10.3^{c}$ & & \\
\hline \multicolumn{7}{|c|}{ End-Member 2 'Weathering' } \\
\hline Model 1 (M1EM2) & 0.72605 & 0.80 & $11.0^{\mathrm{e}}$ & 0.007 & 8 & 23 \\
\hline Model 2 (M2EM2) & $0.72801^{\mathrm{e}}$ & $0.63^{t}$ & $4.6^{\mathrm{e}}$ & 0.003 & 17 & 31 \\
\hline Model 3 (M3EM2) & $0.73629^{9}$ & 0.23 & $4.0^{\mathrm{g}}$ & 0.005 & 42 & 44 \\
\hline
\end{tabular}

Note. Model 1: M1EM2 measured data from RUZS. RUZS is chosen as first order approach to the weathering solution as it is low in $\delta^{98 / 95} \mathrm{Mo}$ and has the highest ${ }^{87} \mathrm{Sr} /{ }^{86} \mathrm{Sr}$ measured here. Model 2: M2EM2: Sr data are taken from the spring (SH) with the highest ${ }^{87} \mathrm{Sr} /{ }^{86} \mathrm{Sr}$ in Pierret et al. (2014). $\delta^{98} \mathrm{Mo}$ is deduced via the $\delta^{98 / 95} \mathrm{Mo}$ $\mathrm{SO}_{4}{ }^{2-}$ correlation (see figure 10). Model 3: M3EM2: Sr data: modeled weathering solution from Probst et al. (2000) (see text). $\delta^{98 / 95}$ Mo taken from average rock; Mo concentration adjusted so the model fits to the outlet composition.

a percentage of element in outlet flow that originates from seawater source

${ }^{b}$ McArthur et al., 2006; Krabbenhöft et al., 2009

Siebert et al. 2003, $\square$ Nakagawa et al. (2012) recalc. following Nägler et al. (2017)

de Villiers (1999)

e Pierret et al. (2014)

${ }^{f}$ from correlation with $\mathrm{SO}_{4}{ }^{2-}$

${ }^{9}$ modeled value, Probst et al. (2000) 


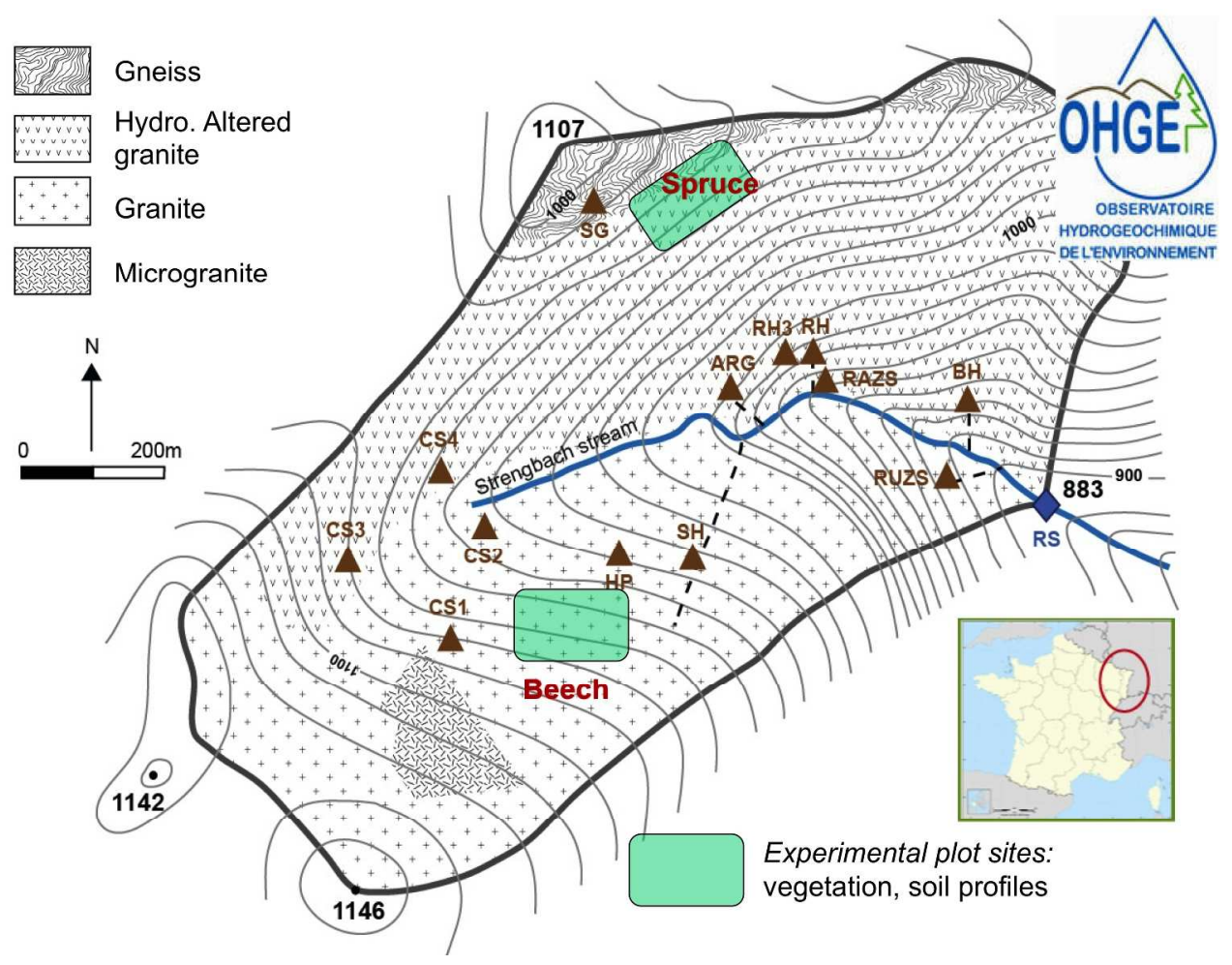

Fig. 1: Location and geological overview and of the Strengbach catchment. Triangles represent springs and stream water locations. Inset: sketch map of France with the position of the Strengbach catchment. 


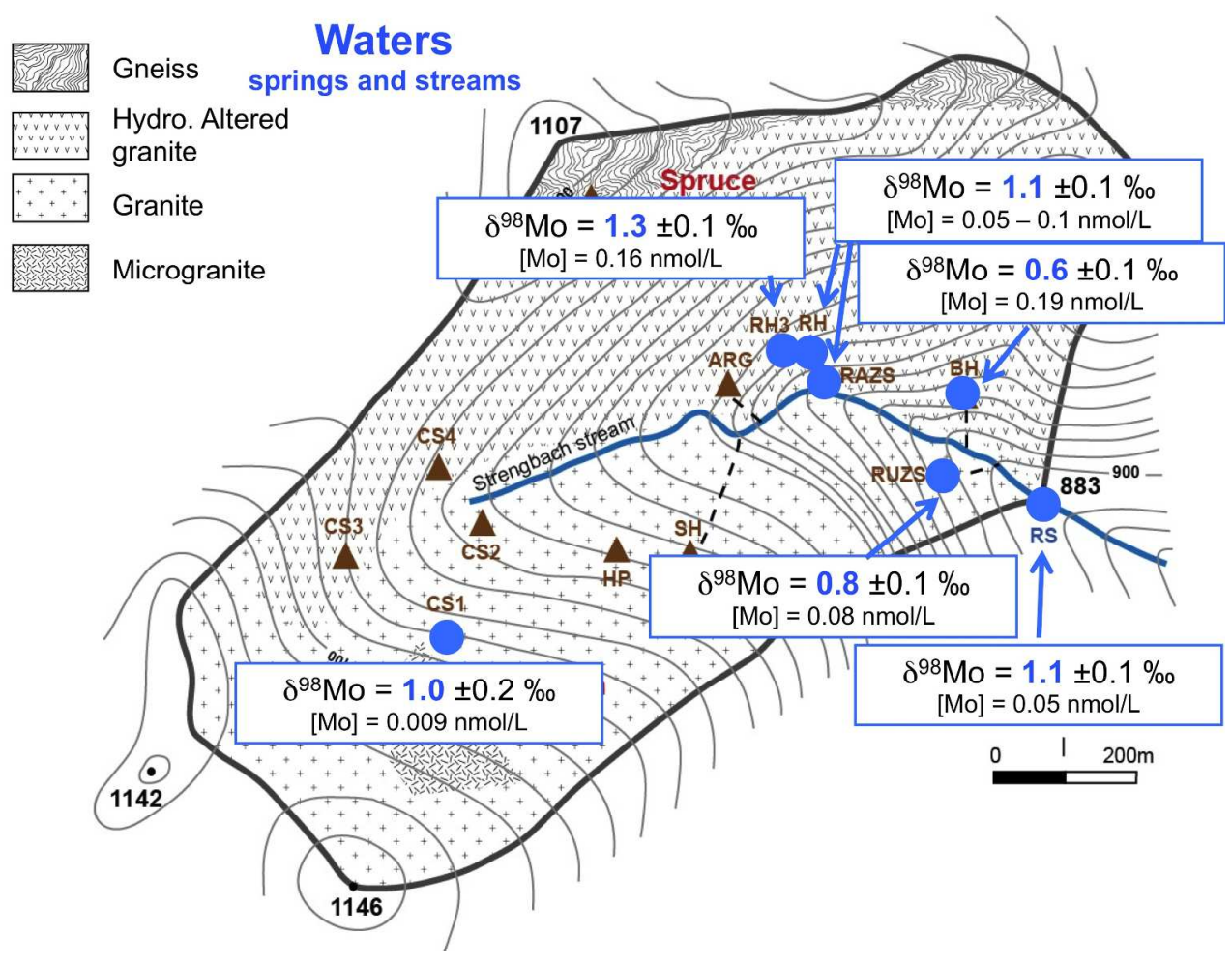

Fig. 2: Locations of sampled waters as well as $\delta^{98 / 95}$ Mo and Mo concentration data (full data in Table 1). $1057 \times 793 \mathrm{~mm}(72 \times 72 \mathrm{DPI})$ 


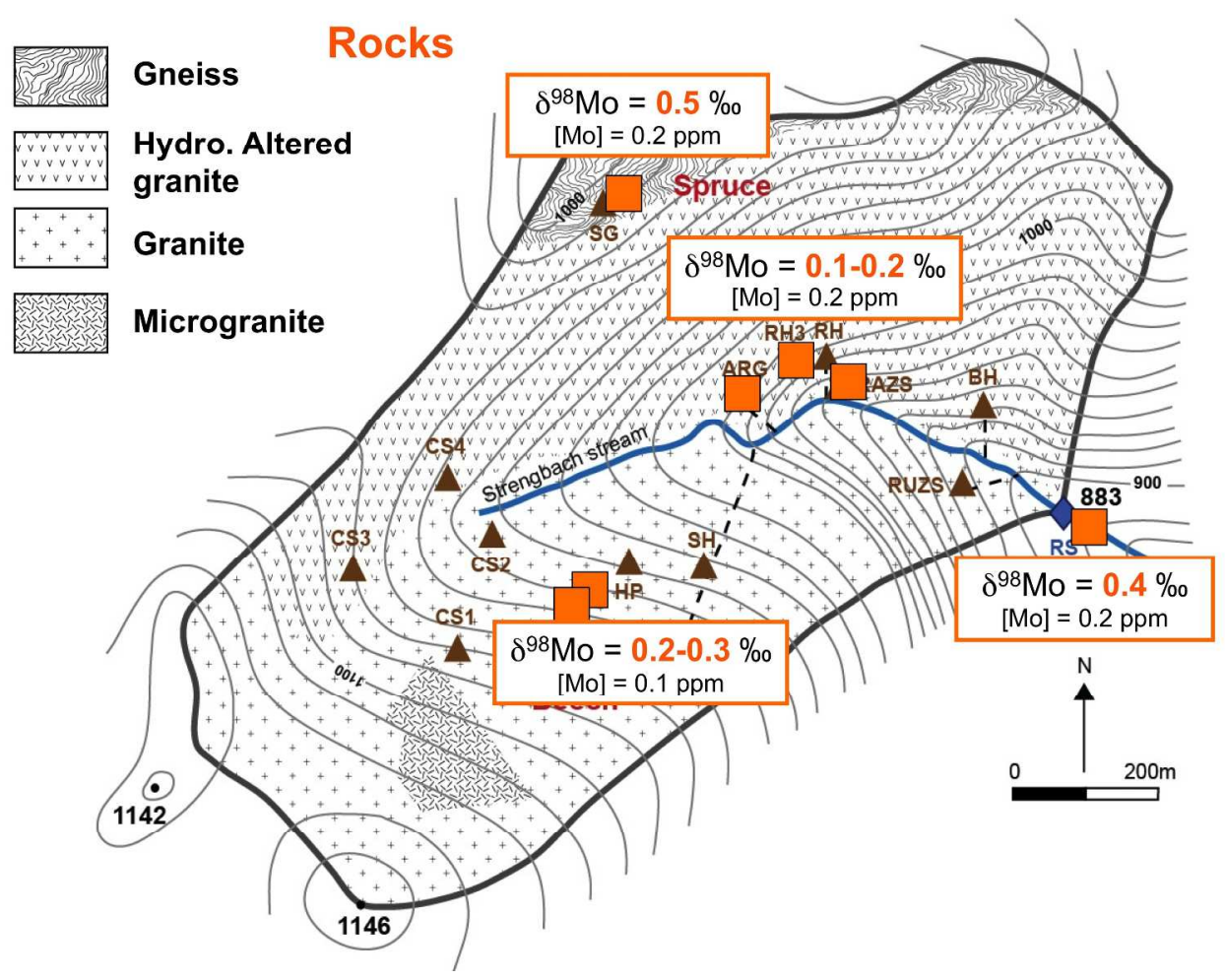

Fig. 3: Locations of rock samples as well as whole rock $\delta^{98 / 95} \mathrm{Mo}$ and Mo concentration data (full data in Table $5)$. 


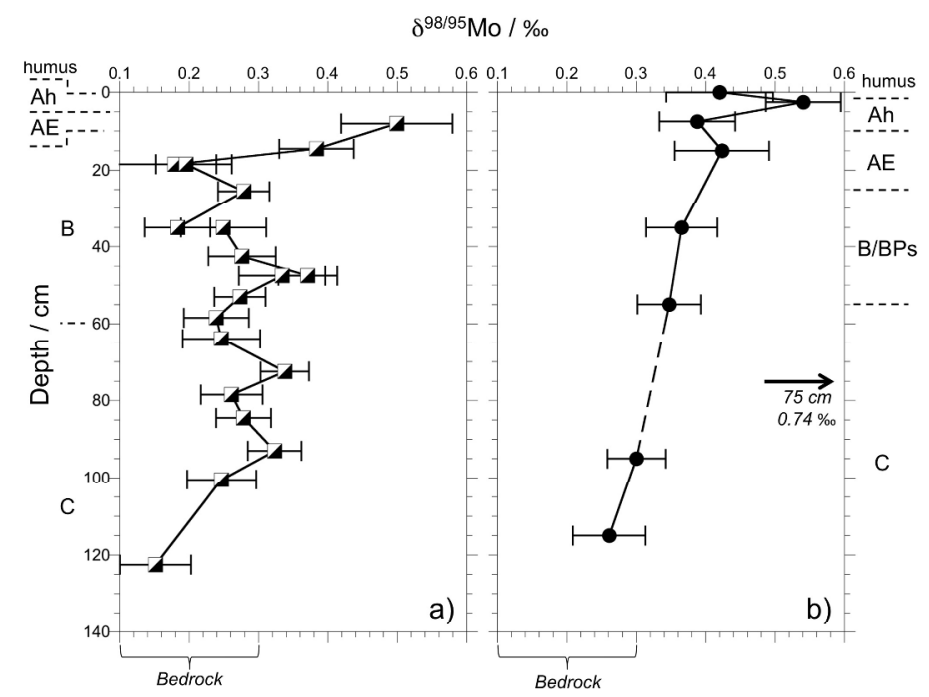

Fig. 4: $\delta^{98 / 95}$ Mo variations in two soil profiles investigated. a) $\delta^{98 / 95} \mathrm{Mo}$ in the soil profile at the Spruce plot, b) $\delta^{98 / 95} \mathrm{Mo}$ in the soil profile at the Beech plot. Deep soil samples fall within the range of fresh bedrock granites. Topsoils have $\delta^{98 / 95}$ Mo values in the range of organic material (see below), but lower than $\delta^{98 / 95} \mathrm{Mo}$ values of surface waters.

$1057 \times 793 \mathrm{~mm}(72 \times 72 \mathrm{DPI})$ 

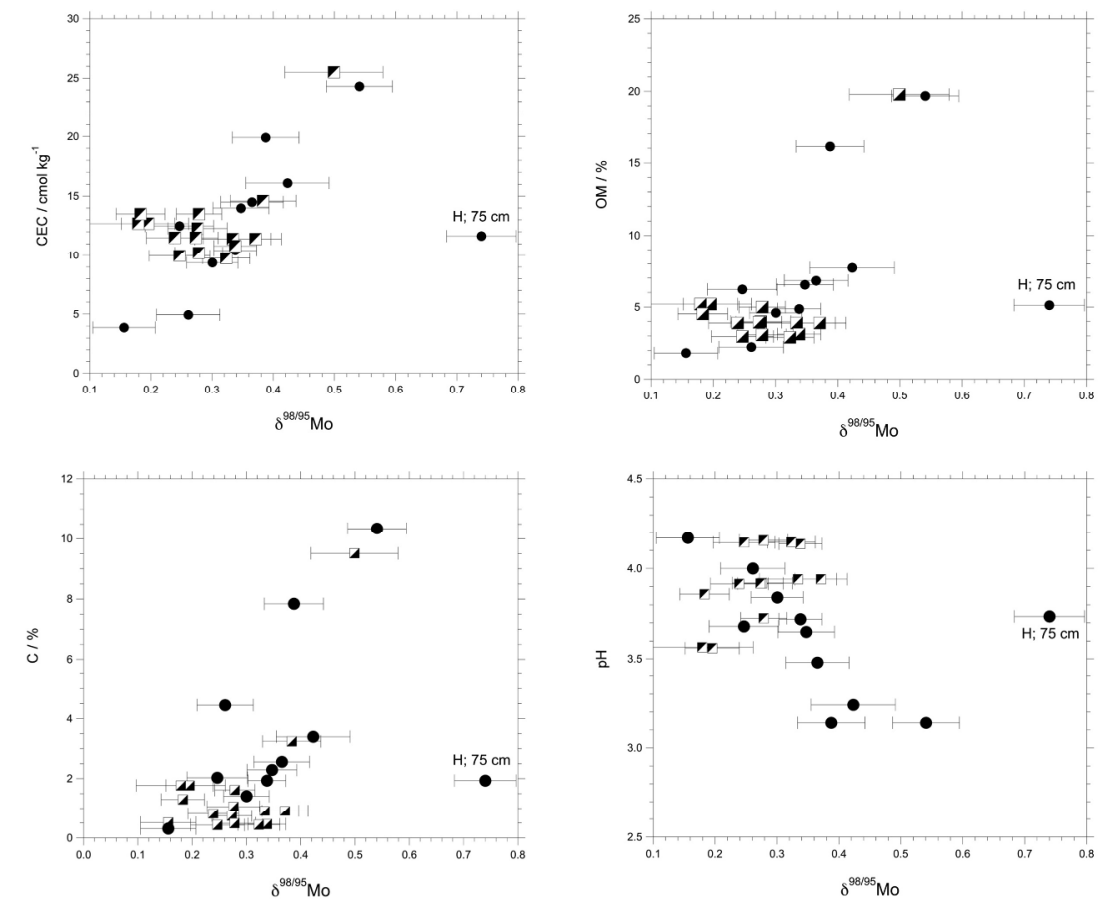

Fig. 5: Diagrams showing $\delta^{98 / 95}$ Mo vs. soil parameters ). Symbols as in Figure. 4. $\delta^{98 / 95}$ Mo correlates positively with cation exchange capacity (CEC), organic matter and carbon content. Organic carbon content appears to be the main factor controlling Mo isotope composition in soils.

$1057 \times 793 \mathrm{~mm}(72 \times 72 \mathrm{DPI})$ 


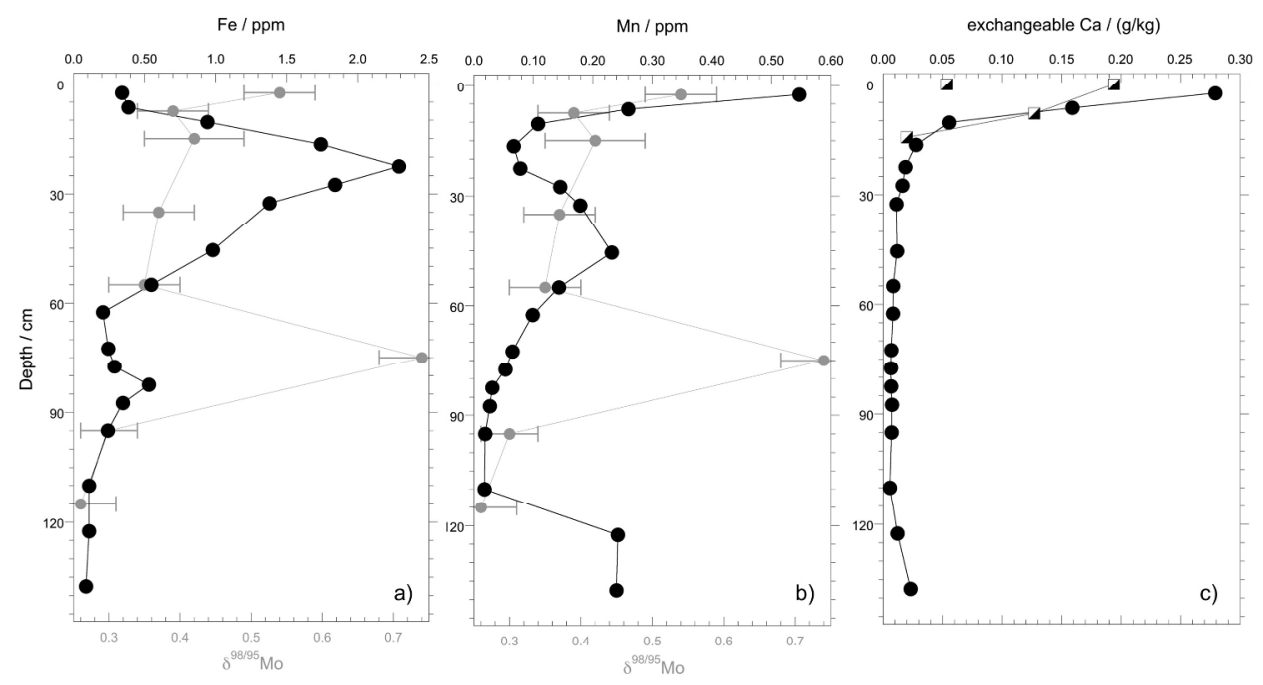

Fig. 6 a,b: Soil profiles illustrating Fe and Mn concentrations vs. depth for the soil profile of the beech plot (HP) (lines and symbols in grey: $\delta^{98 / 95}$ Mo data plotted for reference).

There is no significant net effect of Fe or Mn concentration on $\delta^{98 / 95} \mathrm{Mo}$. Diagram c shows exchangeable Ca vs. depth for both soil profiles. The enrichment of $\mathrm{Ca}$, in the topsoils indicates that $\mathrm{Ca}$ is highly biologically recycled in this environment.

$1057 \times 793 \mathrm{~mm}(72 \times 72$ DPI $)$ 


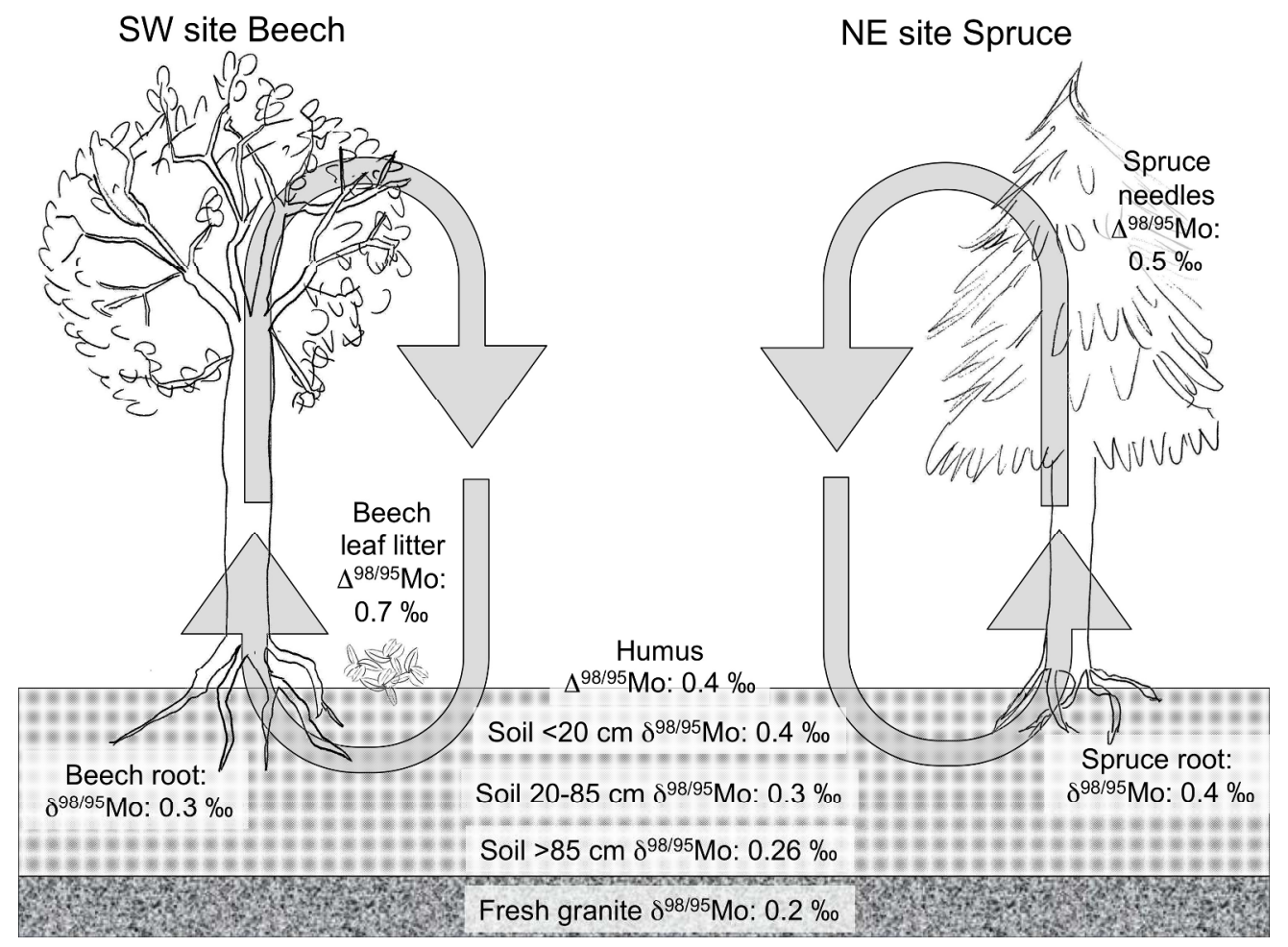

Fig. 7: Molybdenum isotope cycle in vegetation and soils of Fig. 7: Diagram showing Mo isotope cycle in vegetation and soils of the Strengbach catchment. The Mo isotope composition of foliage, litter, roots, humus, and topsoil is rather homogeneous. Apparently, there is an efficient Mo recycling from plants to organic litter to plants, limiting the Mo loss from the ecosystem. Net biological fractionation is subordinate to the differences in the Mo sources. Samples from intermediate depth can be interpreted as mixture between organic matter and weathered bedrock, as Carbon and organic matter content decrease with depth. 


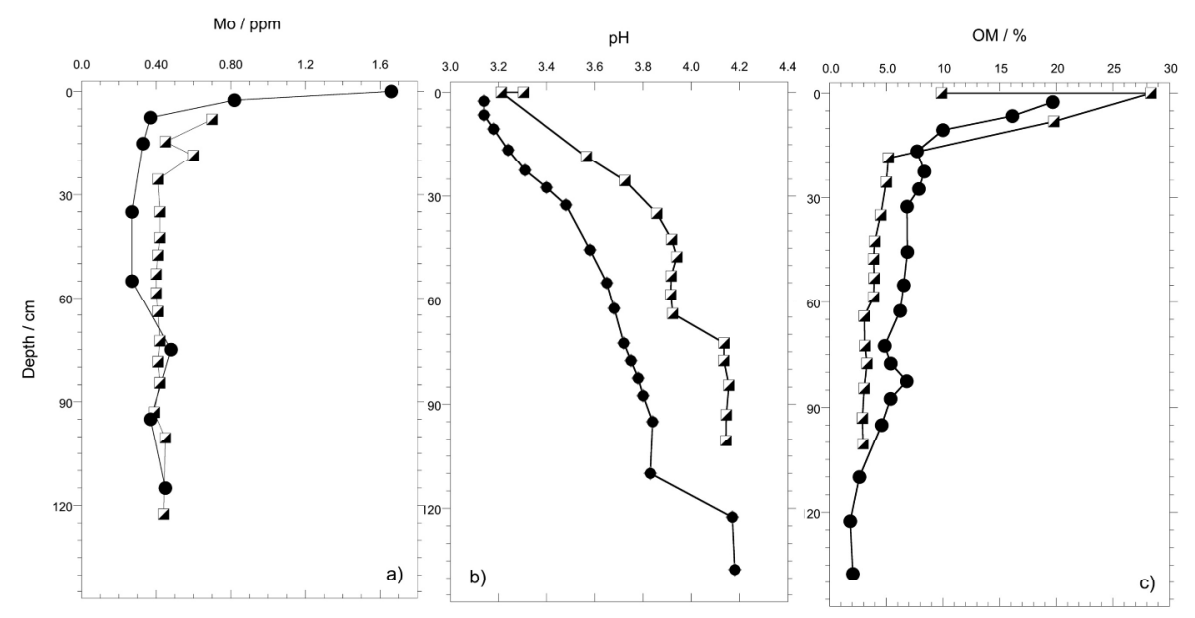

Fig. 8: Soil profile illustrating Mo concentrations, $\mathrm{pH}$ and organic matter vs. depth. Symbols as in Fig. 4 . Mo mimics exchangeable $\mathrm{Ca}$, (Fig. 6) which is highly biologically recycled in this environment. This supports the hypothesis of efficient recycling of Mo in the biological cycle, Further, organically bound Mo appears to be important to reduce Mo loss from the system.

$1057 \times 793 \mathrm{~mm}(72 \times 72$ DPI $)$ 


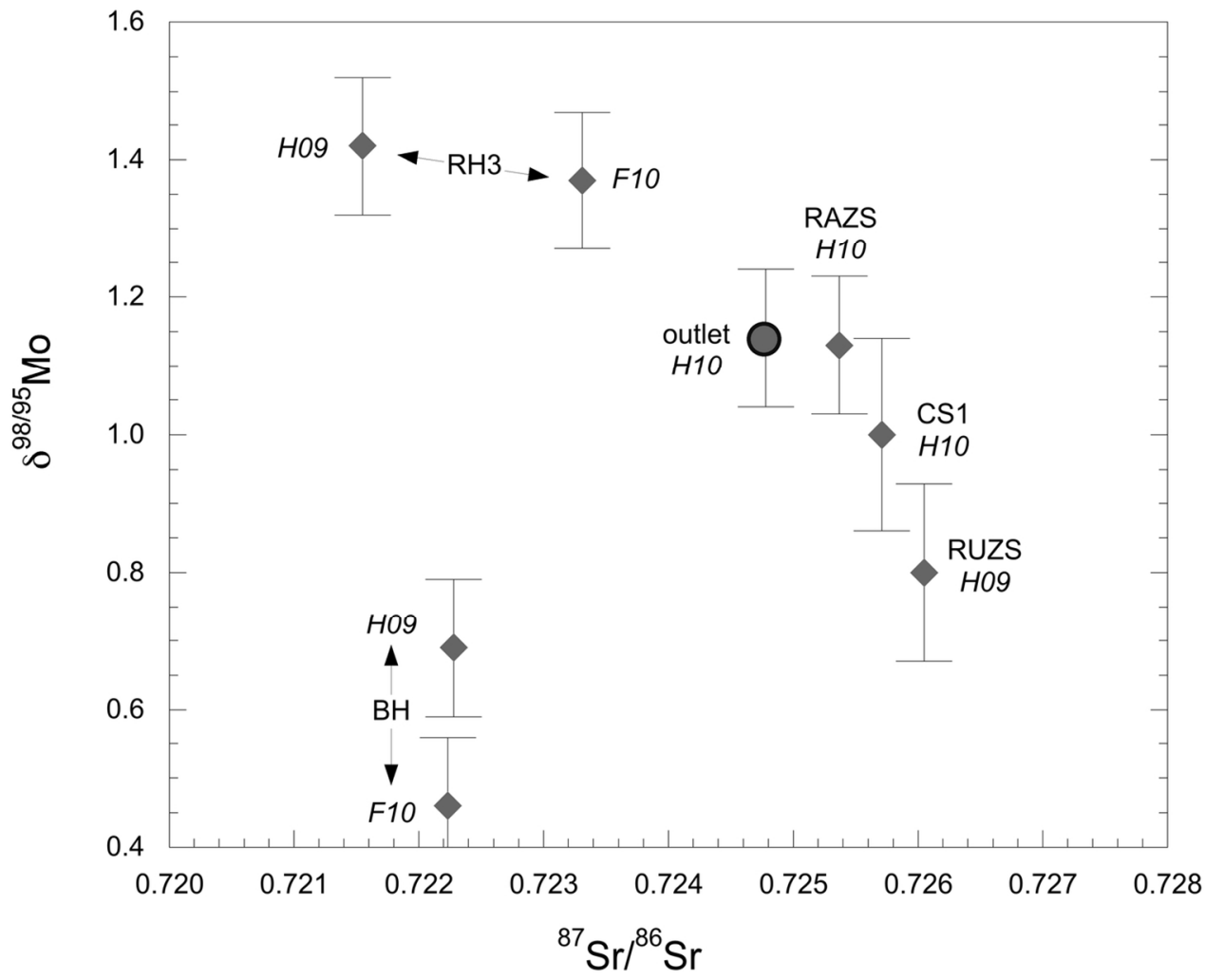

Fig. 9: $\delta^{98 / 95} \mathrm{Mo} v \mathrm{~s} .{ }^{87} \mathrm{Sr} /{ }^{86} \mathrm{Sr}$ diagram showing waters from the Strengbach catchment (Table 1 ). With the exception of one sample $(\mathrm{BH})$, the data show a clear (curved) negative correlation. Error bars represent $2 \sigma$ uncertainty of $0.1 \%$ (external reproducibility of water samples). If a particular in-run uncertainty is higher, then the latter is shown. H09, H10: autumn 2009 and 2010 respectively, F10 = spring 2010.

$126 \times 102 \mathrm{~mm}(300 \times 300 \mathrm{DPI})$ 


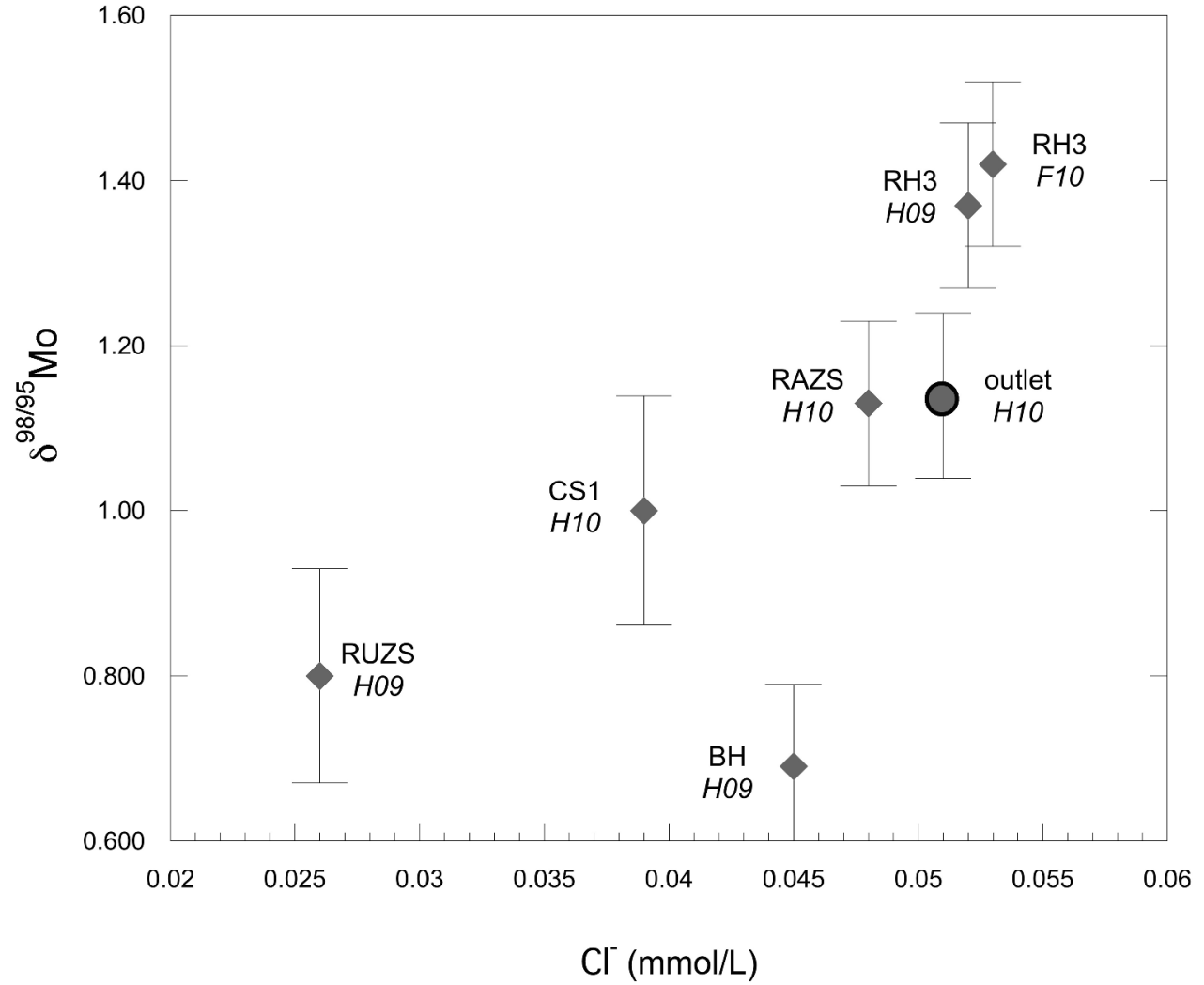

Fig. 10: $\delta^{98 / 95} \mathrm{Mo}$ vs. $\mathrm{Cl}^{-}$diagram showing waters of the Strengbach catchment. Again sample $\mathrm{BH}$ is an outlier, the other samples being positively correlated. Uncertainties and labels as in figure 9. 


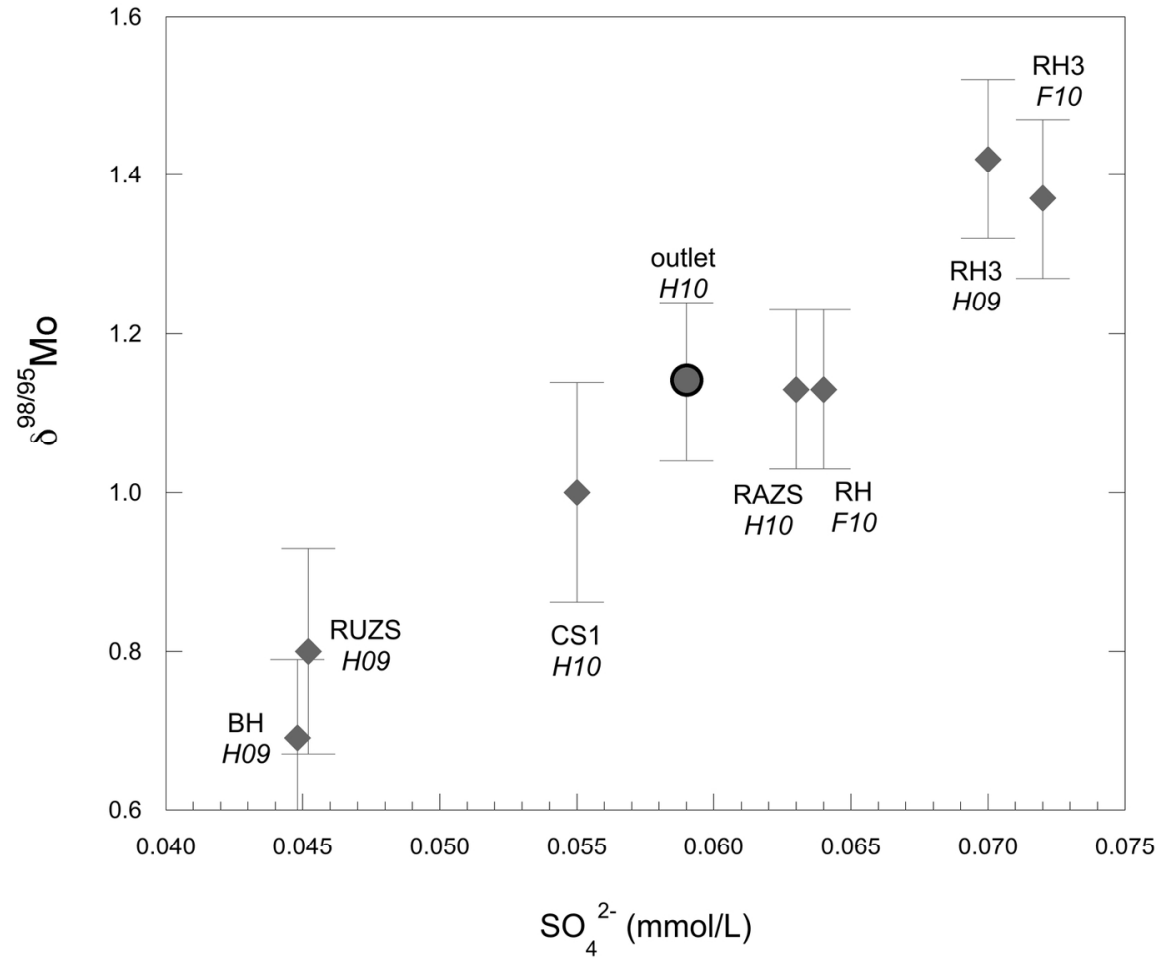

Fig. 11: $\delta^{98 / 95} \mathrm{Mo}$ vs. $\mathrm{SO}_{4}{ }^{2-}$ diagram showing waters of the Strengbach catchment. Uncertainties and labels as in figure 9.

$160 \times 148 \mathrm{~mm}(300 \times 300 \mathrm{DPI})$ 


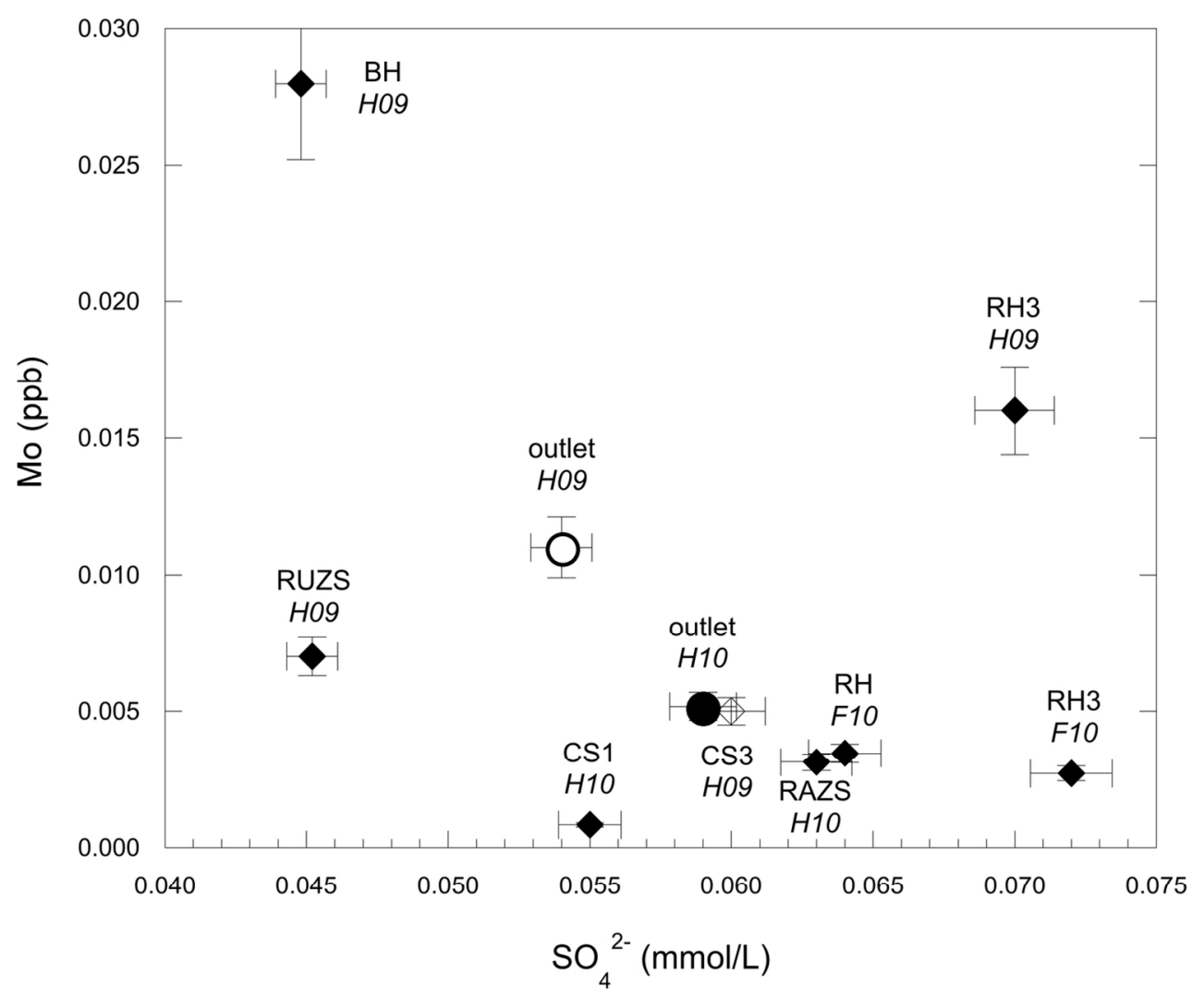

Fig. 12: Mo concentration of waters of the Strengbach catchment relative to $\mathrm{SO}_{4}{ }^{2-}$ (Table 1 ). Open symbols: samples with no $\delta^{98 / 95}$ Mo data.

$129 \times 108 \mathrm{~mm}(300 \times 300$ DPI $)$ 


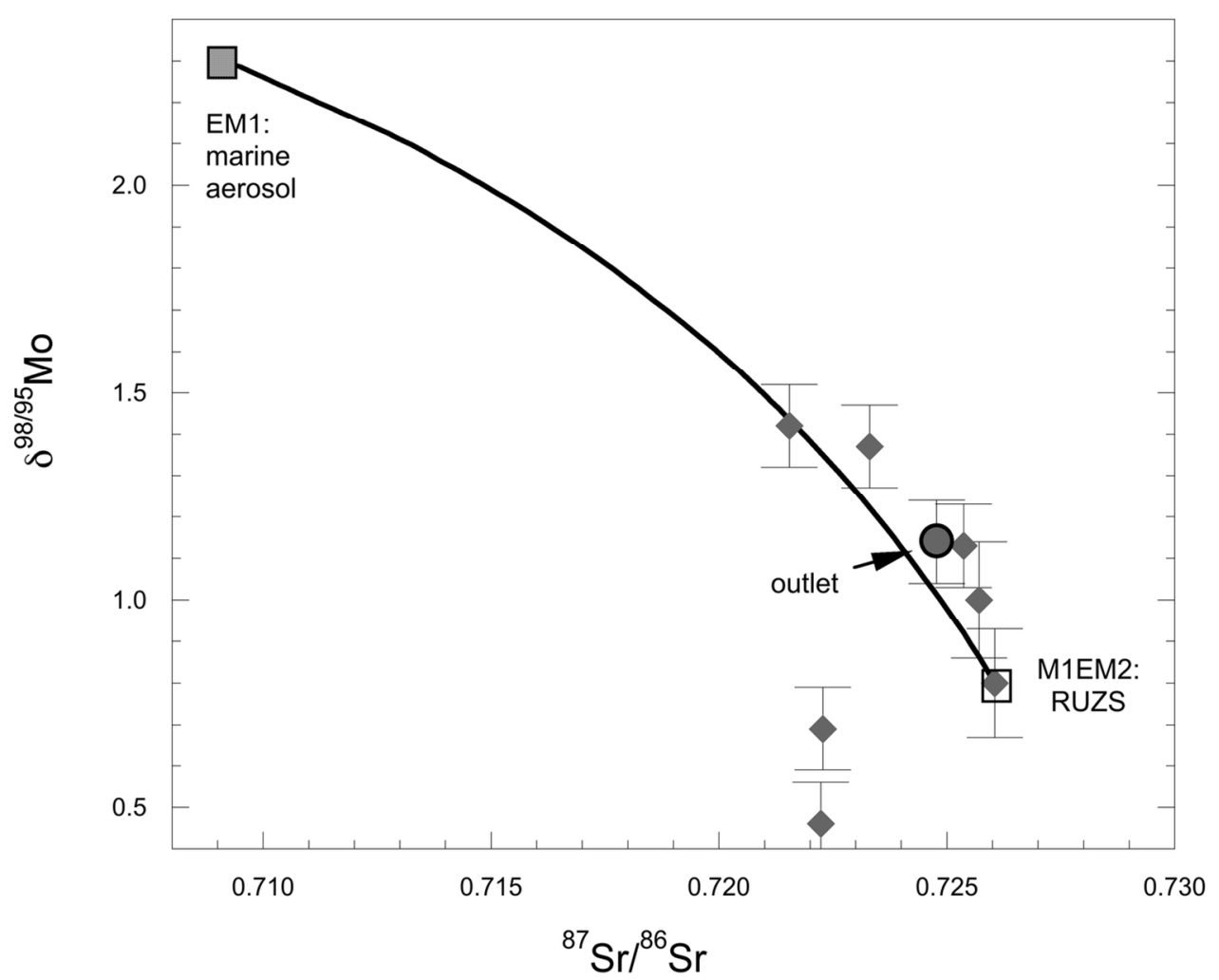

Fig. 13: $\delta^{98 / 95} \mathrm{Mo}$ vs. ${ }^{87} \mathrm{Sr} /{ }^{86} \mathrm{Sr}$ diagrams showing the results of model 1 together with the measured water samples of the Strengbach catchment. Model 1 assumes a binary mixing of a marine aerosol end member (EM1), and the second end member M1EM2 representing a weathering source. In Model 1 the unknown M1EM2 is approached by the measured data of the water sample showing the least potential marine aerosol influence, i.e. with low $\delta^{98 / 95} \mathrm{Mo}$, lowest Mo concentration, and highest ${ }^{87} \mathrm{Sr} /{ }^{86} \mathrm{Sr}$ (RUZS). This approach reduces the number of assumptions compared to models 2 and three below, but the sample values do not represent the ultimate weathering endmember. The points shown are the same as in figure 9; labels are omitted for clarity. Error bars as in figure 9. Model parameters are listed in Table 8. 


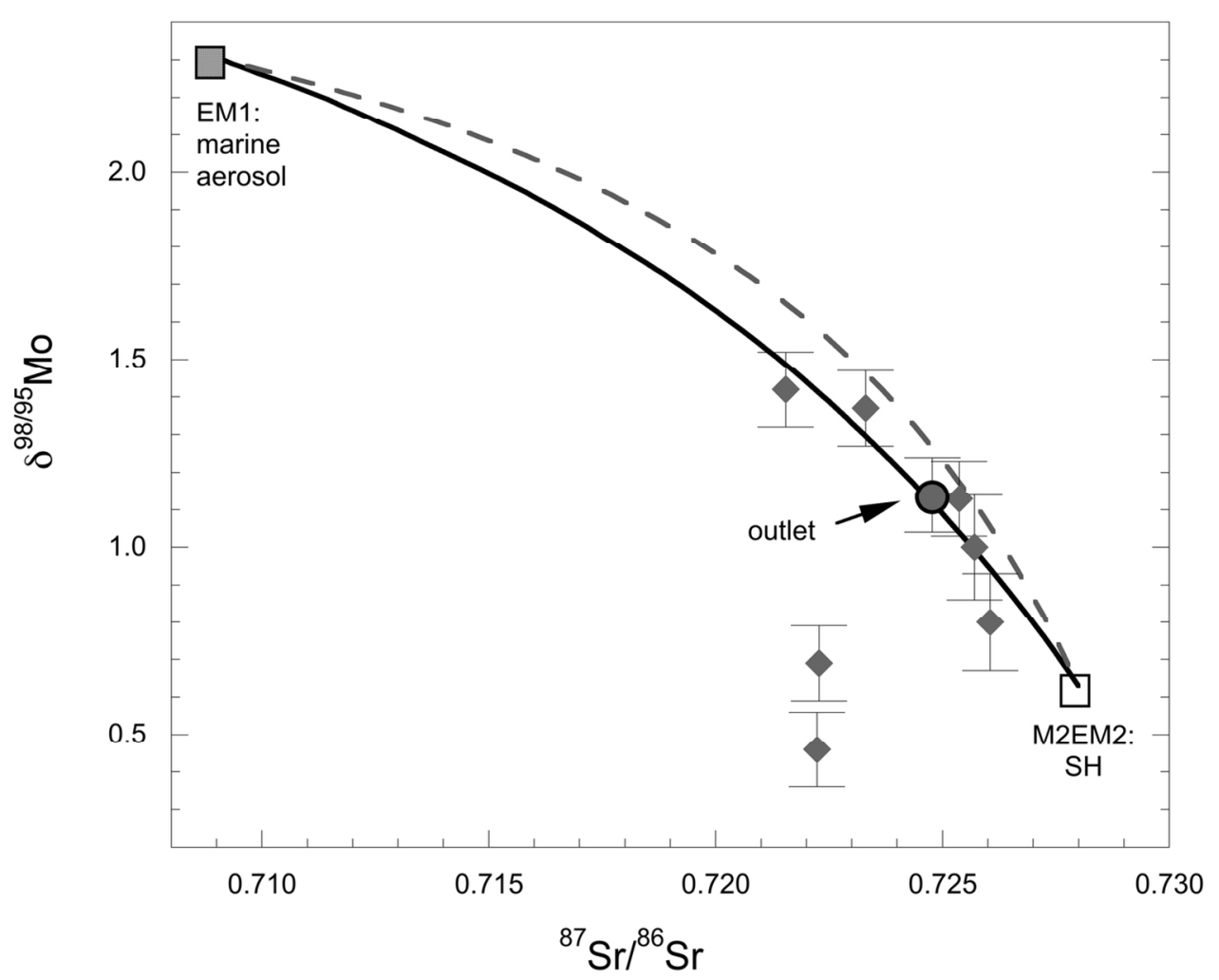

Fig. 14: $\delta^{98 / 95} \mathrm{Mo}$ vs. $87 \mathrm{Sr} /{ }^{86} \mathrm{Sr}$ diagram showing the results of model 2 together with the measured water samples of the Strengbach catchment. Model 2 assumes the same end member (EM1) as in model 1. In Model 2 the unknown weathering source M2EM2 is approached by ${ }^{87} \mathrm{Sr} /{ }^{86} \mathrm{Sr}$ data taken from the spring (SH) with the highest ${ }^{87} \mathrm{Sr} /{ }^{86} \mathrm{Sr}$ in Pierret et al. (2014), i.e. a sample potentially being closer to the true weathering solution. The unmeasured $\delta^{98 / 95} \mathrm{Mo}$ of this sample is deduced independently via the $\delta^{98 / 95} \mathrm{Mo}-$ $\mathrm{SO}_{4}{ }^{2-}$ correlation (Fig. 11). Solid line: calculation assumes a ratio MeEM2 Sr/Mo of 1500 identical to the ratio in Model 1. Dashed line: Model calculated with a MeEM2 Sr/Mo of 2245, slightly above the value of the outlet (2200). Error bars as in fig. 9. Model parameters are listed in Table 8.

$126 \times 102 \mathrm{~mm}(300 \times 300 \mathrm{DPI})$ 


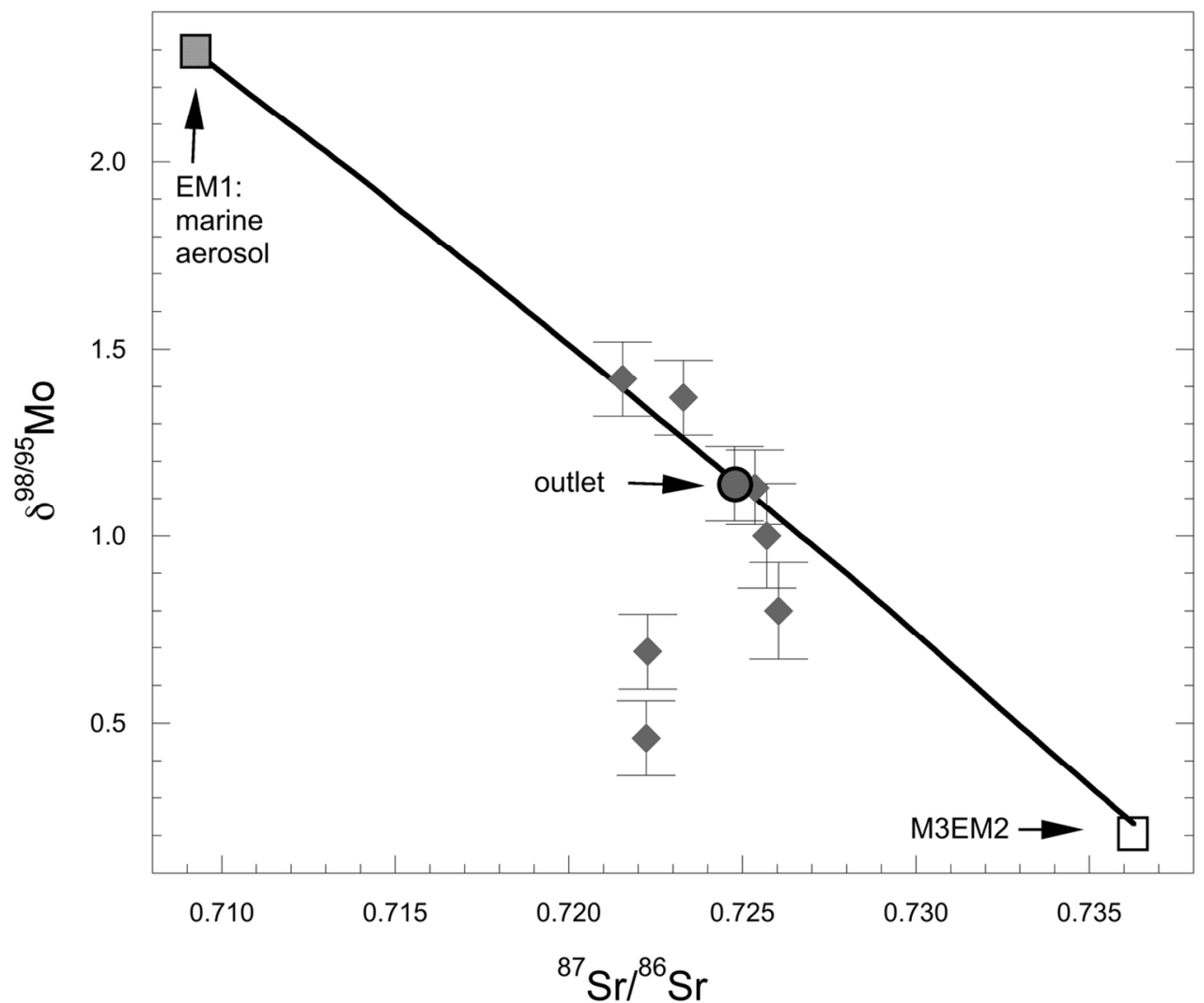

Fig. 15: $\delta^{98 / 95} \mathrm{Mo}$ vs. ${ }^{87} \mathrm{Sr} /{ }^{86} \mathrm{Sr}$ diagram showing the results of model 3 together with the measured water samples of the Strengbach catchment Model 3: assumes the same end member (EM1) as in model 1. In Model 3 the unknown weathering source M3EM2 is approached by ${ }^{87} \mathrm{Sr} /{ }^{86} \mathrm{Sr}$ and $\mathrm{Sr}$ concentration from a modelled weathering end member of Probst et al. (2000) (see text). $898 / 95 \mathrm{Mo}$ is assumed to be equal to average bedrock; Mo concentration adjusted to match the outlet composition. The resulting Sr/Mo of M3EM2 is 800 , i.e. lower than for the first two models, and very similar to ocean water, resulting in an almost straight line. Sr/Mo of waters in the catchment, however, are $>1000$. Error bars as in fig. 9. Model parameters are listed in Table 8.

$126 \times 107 \mathrm{~mm}(300 \times 300$ DPI $)$ 